Article

\title{
System Dynamics Applied to Terraced Agroecosystems: The Case Study of Assaragh (Anti-Atlas Mountains, Morocco)
}

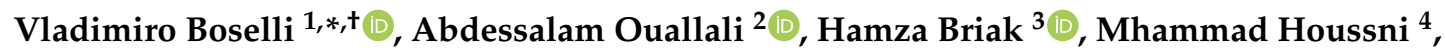 \\ Jalal Kassout ${ }^{4} \mathbb{D}$, Abdeltif El Ouahrani ${ }^{4}$ and Eleni Maria Michailidi ${ }^{5,+} \mathbb{D}$ \\ 1 Dipartimento di Ingegneria Civile, Architettura, Territorio, Ambiente e di Matematica (DICATAM), \\ Università degli Studi di Brescia, Via Branze, 43, 25123 Brescia, Italy \\ 2 Department of Geology, Abdelmalek Essaadi University, Avenue Sebta, Tétouan 93002, Morocco; \\ abdessalamouallali@gmail.com \\ 3 Center for Soil and Fertilizer Research in Africa (CESFRA), Mohammed VI Polytechnic University, \\ Lot 660, Hay Moulay Rachid, Ben Guerir 43150, Morocco; hamza.briak@um6p.ma \\ 4 Department of Biology, Abdelmalek Essaadi University, Avenue Sebta, Tétouan 93002, Morocco; \\ mhammadhoussni@gmail.com (M.H.); jalalkassout@gmail.com (J.K.); elouahrani@gmail.com (A.E.O.) \\ 5 Direzione Difesa del Suolo, Regione del Veneto, Palazzo Linetti, Calle Priuli 99, 30121 Venice, Italy; \\ elenimaria.michailidi@regione.veneto.it \\ * Correspondence: v.boselli@unibs.it \\ + These authors contributed equally to this work.
}

Received: 30 April 2020; Accepted: 9 June 2020; Published: 13 June 2020

\begin{abstract}
Terraced agroecosystems (TAS)—apart from being an important cultural heritage elementare considered vital for sustainable water resource management and climate change adaptation measures. However, this traditional form of agriculture, with direct implications in food security at a local scale, has been suffering from abandonment or degradation worldwide. In light of this, the need to fully comprehend the complex linkage of their abandonment with different driving forces is essential. The identification of these dynamics makes possible an appropriate intervention with local initiatives and policies on a larger scale. Therefore, the main aim of this paper is to introduce a comprehensive multidisciplinary framework that maps the dynamics of the investigated TAS's abandonment, by defining cause-effect relationships on a hydrogeological, ecological and social level, through tools from System Dynamics studies. This methodology is implemented in the case of Assaragh TAS, a traditional oasis agroecosystem in the Moroccan Anti-Atlas, characterized by data scarcity. Through field studies, interviews, questionnaires and freely accessible databases, the TAS's abandonment, leading to a loss in agrobiodiversity, is linked to social rather than climatic drives. Additionally, measures that can counteract the phenomenon and strengthen the awareness of the risks associated with climate change and food security are proposed.
\end{abstract}

Keywords: terraced landscapes; agroecosystems; system dynamics; climate change

\section{Introduction}

Terraced landscapes represent one of the oldest and most efficient forms of human adaptation to cultivate in harsh environments [1-3]. In the Mediterranean area, this technique is especially adopted to cultivate marginal or sloppy lands from the small island (e.g., Sicily in South Italy, Cyclades in Greece) to the arid slopes of the Atlas Mountains in Morocco [4-7]. Terraced landscapes are increasingly considered as a valuable cultural, historical, religious and ecological heritage for humanity. The valuable agricultural biodiversity, the important ecosystems resiliency and the high cultural 
heritage hosted by local communities in these agroecosystems are main features of an outstanding traditional agricultural landscapes as described by the Globally Important Agricultural Heritage Systems (GIAHS) program of the FAO [8]. Moreover, these landscapes are considered in the center of a sustainable dynamic conservation system of biological resources and its associated traditional knowledge of agroecosystems management [9]. At the base of the terraced landscaper there is "The art of dry stone walling [...] the know-how related to making stone constructions by stacking stones upon each other, without using any other materials except sometimes dry soil" as inscribed in the List of the Intangible Cultural Heritage of Humanity by the UNESCO in December 2018 [10] (Inscription: 13.COM 10.b.10, No. 01393).

In agricultural terms, terraces are considered as a crucial component of complex agroecosystems adopted by farmers in marginal environments, namely areas with poor soil quality and with little or no agricultural value, particularly vulnerable to climate change, water scarcity and salinity $[7,11]$. Terraced agroecosystems (TAS) support many types of cultivation modes, as seasonal crops [12] or more admixed cultural practices associating seasonal crops with perennial ones as in the case of the Rif [13] and Anti-Atlas mountains of Morocco [7]. These characteristics of TAS are the main features of traditional agroforestry systems supporting agrosilvopastoral activities [14]. However, under arid environments, where agriculture is not possible without irrigation, TAS can be considered as major components of traditional oasis agroecosystems [15]. Furthermore, in analogy with the definition of biodiversity hotspot [16], traditional agroecosystems holding TAS could be considered as a main zone for conserving crop biodiversity and local landraces $[17,18]$.

On the other hand, TAS create a new equilibrium with the ecosystem and the water cycle, significantly altering the ecological and hydrological balance in a sustainable manner by maintaining water conservation and regulation, slope stabilization and soil erosion control [12,19]. In fact, traditional irrigation and landscaping techniques used in terraces were identified as key aspects of soil conservation and agricultural practices [20] to build living and autopoietic ecosystems in adverse climatic conditions, and to adapt to climatic variations.

Today, these agroecosystems that culturally bind the people worldwide, are in decline. The development of more modernized agriculture and the rural exodus events have significantly contributed, in general, to the marginalization of traditional agriculture practices [11] and consequently the abandonment of TAS [21], and their transformation to uphill cultivations in many regions [12,22]. Many authors $[7,23,24]$ highlighted some issues related to the conservation of TAS across the Mediterranean, which can be summarized in four key problems: changes in landscapes use and management, hydrological instability due to rainfall regime changes, soil erosion and slope failures and loss of traditional knowledge associated with traditional agriculture practices used in TAS.

This inherent multifacetedness of the issue has created a great difficulty in promoting policies that can effectively preserve terraces and their functionality. In fact, Fischer at al. [25] seem to have really grasped the essence, highlighting that "a preservation strategy can be successful in the short term, but it fails to acknowledge that traditional farming landscapes evolved as tightly coupled social-ecological systems". Therefore, a comprehensive approach of the problem should consider the different aspects contributing to the TAS abandonment. Although, several important studies investigate the effects of different drives (e.g., geology, climate, etc.), individually [12,21,26-29], there seems to be a scientific gap on the combined consideration of all the often interconnected different aspects that can act upon the status of TAS.

The present study aims to define the driving forces on a hydrogeological, ecological, agricultural and social level, that can contribute to the abandonment of terraces and to incorporate them into a combined framework at the service of stakeholders and policy makers. In order to tackle the complexity stemming from the heterogeneity of drivers, it has been adopted a system dynamics (SD) methodology, previously used for other complex water-related and agroecosystem modelling problems [30-34]. To the authors' knowledge, this is the first study that applies SD in the context of TAS. The developed SD methodological framework can be implemented in any given scenario 
and can be useful for integrating qualitative and quantitative assessments of multidisciplinary nature that can even be interconnected [35]. Moreover, its applicability in cases with data scarcity allows to address issues in those areas of the world which often are more vulnerable, poorer and marginalized. The latter consequently suffer from a lack of interest in monitoring environmental and social variables, properly [36].

In order to test this approach, the SD methodology has been applied in the Assaragh TAS-an oasis in the Anti-Atlas of Morocco characterized by a traditional agroforestry system - affected by lack of data. In this context, extensive field studies, questionnaires, interview, freely accessible databases, as well as wadi (see Appendix A for specific terms) hydrological methods and agroecosystems monitoring, have contributed in comprehending the nature and causes of the phenomenon, which in this case covered principally the social and cultural spectrum. Preventive and improvement measures were finally proposed. Despite its limitations, the authors believe that the methodology presented can be a useful tool for analyzing and tackling the problem of TAS's degradation, when adapted on a case-by-case basis.

\section{Materials and Methods}

\subsection{Case Study}

Morocco, a country very vulnerable to the effects of climate change [37], since 2008, has been working on a national strategy for sustainable agricultural and food security development, known as Morocco Green Plan (MGP) [38]—today updated as Génération Green 2020-2030 [39]—aiming to modernize the agricultural sector in order to become more competitive in global markets and to promote sustainable management of natural resources. However, this general idea of modernization in marginal environments, such as the oasis in the arid Anti-Atlas, can give rise to great contradictions and problems [40]. Schilling et al. [41], in fact, noticed discrepancies in the MGP and recommended switching the focus from maximization of agricultural production to output stabilization. In this sense, TAS - very often found in Morocco-plays a fundamental role in reducing the loss of organic matter and soil moisture, helping to maintain the production capacity in a climate change scenario ([7]) and thus preserving food security at the local scale.

\subsubsection{General Overview}

The basin of Assaragh (or Assrargh, or also Asrargh, depending on the translitteration)—named after the village located in the south of the basin-is situated in the Anti-Atlas region of Morocco on the boundary between the Drâa-Tafilalet and the Sous-Massa region (see Figure 1b). Administratively, it is part of the Souss-Massa region and is located north of the province of Taroudannt, south of Tata and east of Agadir-Melloul.

From a phytogeographical point of view Assaragh basin is situated at the limit of the sclerophyllous forest characterized by the presence of sclerophyllous trees such as Juniperus phoenicea and fragmented plots of Quercus ilex [42,43] and thus, belongs to the arid infra-Mediterranean vegetation zone [44]. The region is under strong Saharan influences characterized by climatic aridity and low rainfall [45]. The hydrographic network of the basin has a north-south orientation and is of torrential nature, thus, drying up most of the year. Its main creek, assif Aguinane, passes through the village of Assaragh, whose oasis is mainly irrigated by springs and wells. The main characteristics of the basin are presented in Table 1.

Along the assif and the oases, several villages (or ksours) are settled, whose emergence was facilitated by the water stored in karst limestones, feeding the oases. As an observer leaves the basin outlet and proceeds more upstream, the following villages are encountered: Assaragh, Lemdint, Iguerda and Timdghart (Figure 1c). The total population living along the course of the assif Aguinane is 2875 inhabitants, of which 1330 live in the upstream assif branch within the investigated area (details in Table A1). 
Table 1. Main characteristics of the study basin.

\begin{tabular}{ccc}
\hline Parameter & Value & Dimension \\
\hline Basin area & 87 & $\mathrm{~km}^{2}$ \\
Perimeter & 72 & $\mathrm{~km}$ \\
Length of the main branch (or assif) & 24 & $\mathrm{~km}$ \\
Maximum altitude & 2038 & $\mathrm{~m}$ asl \\
Average altitude & 1818 & $\mathrm{~m}$ asl \\
Minimum altitude at closing section & 1506 & $\mathrm{~m}$ asl \\
Maximum distance between basin and closing section & 15 & $\mathrm{~km}$ \\
Average slope of the basin & 23.50 & $\%$ \\
Average slope of the main branch (or assif) & 2.84 & $\%$ \\
Concentration time range (see Table A2) & $5.6-1.7$ & $\mathrm{~h}$ \\
\hline
\end{tabular}
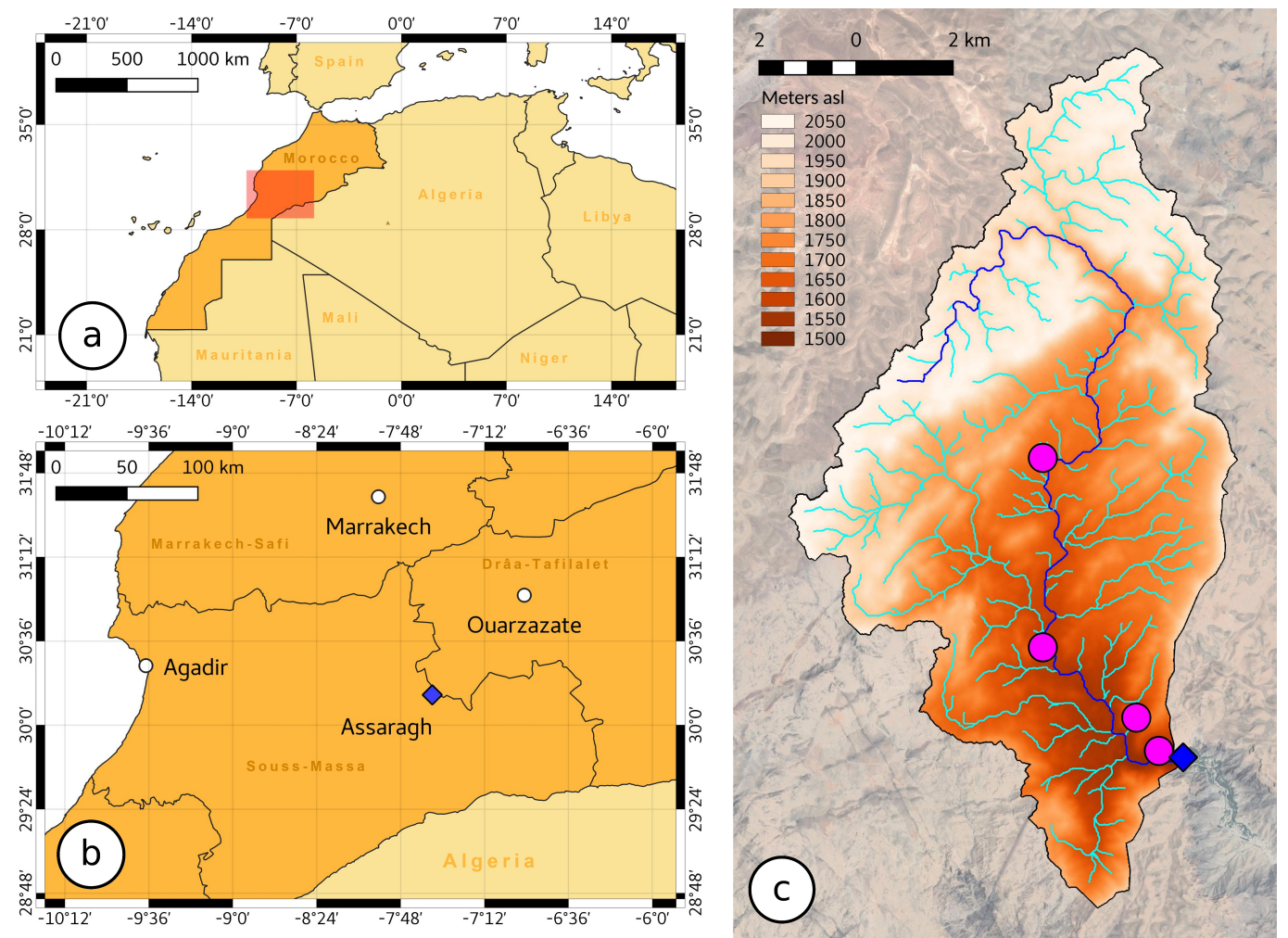

Figure 1. (a) Geographical localization of the region. (b) Location of Assaragh on the border between the Souss-Massa and Drâa-Tafilalet regions. (c) The investigated basin; in deep blue the main wadi stream or assif, in light blue the minor hydrographic network; the deep blue diamond is the closing Section (1506 m asl); in magenta, starting from downstream, the four ksours of Assaragh (1560 m asl), Lemdint (1620 m asl, above the left bank), Iguerda (1620 m asl) and Timdghart (1690 m asl).

\subsubsection{The Assaragh TAS}

The four villages in the Assaragh basin are characterized by the presence of terraces that develop from the bed of the wadi to embrace the inhabited area. Terraces are structurally supported by dry stone walls, made by material recovered on-site; stones are quite irregular and their dimensions range from a diameter of 0.1 to $1 \mathrm{~m}$ with the prevalence of intermediate and small diameters (Figure 2). Much of the structural solidity of the walls is guaranteed by the packing due to the finer soil, mainly clay, which over time fills the empty spaces between the stones.

Agricultural land in Assaragh is managed by small private farms. The possession of the land is private and individual plots are registered to farmers; this legal form of land ownership is called 
melk. The mean size of farms does not exceed 0.5 ha; the smallest farms can count at minimum 3 plots, while the biggest ones can reach a maximum of 30 plots. The small plots may explain the relatively small production outcomes, and thus, the low generated income. The majority of farmers are using traditional ploughs to loosen or turn the soil before sowing seeds or planting trees. Cereal and herbaceous crops are harvested manually using sickles, while animals facilitate the transportation of crops.
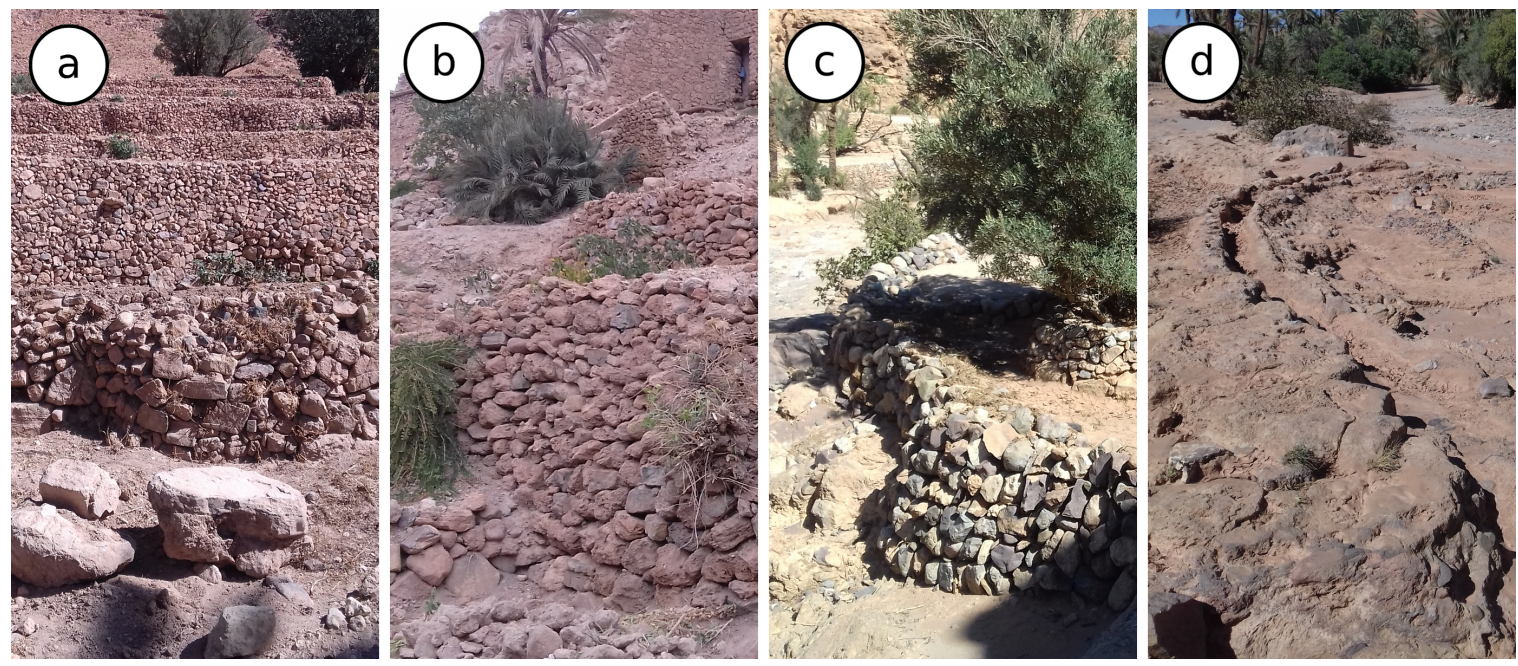

Figure 2. Documentation of the dry stone structures: (a) terraces on a slope, in the foreground a recountouring of the wall in a place broken by a palm tree currently removed, (b) a dry wall with adult plants of Capparis spinosa consolidating it, (c) dry wall structure on the wadi banks, (d) abandoned ancient irrigation channel, crossing the wadi to irrigate the opposite bank.

Unfortunately, throughout the years, Assaragh has seen a gradual abandonment of its terraces. This phenomenon, although more evident for the terraces of Iguerda and Timdghart, is heavily present in Assaragh, as well. As one can note from Table 2, Assaragh and Lemdint have experienced an abandonment of almost $30 \%$ of their pre-existing terraces, while the ratios for Iguerda and Timdghart are above $77 \%$ and $88 \%$, respectively. A general map of the active and abandoned terraces is presented in Figure 3. The TAS in Iguerda and Timdghart, while still retaining residual active terraces, can be considered essentially abandoned since they no longer have a systemic coherence. The few remaining cultivated plots are owned by elder members of few families that produce subsistence food.

Table 2. Abandonment ratio of terraced surface in the three terraced agroecosystems (TAS), calculated as percentage of abandoned terraced surface to the whole TAS surface. The terraces' state is the one observed in 2019, as a diachronic comparison was not feasible. The surfaces have been measured contouring polygons manually, on a satellite imagery base, the results have been validated by a field survey.

\begin{tabular}{cccc}
\hline TAS & Active Terraced Surface & Abandoned Terraced Surface & Abandonment Ratio \\
\hline Assarargh \& Lemdint & $0.367 \mathrm{~km}^{2}$ & $0.154 \mathrm{~km}^{2}$ & $29.6 \%$ \\
Iguerda & $0.056 \mathrm{~km}^{2}$ & $0.190 \mathrm{~km}^{2}$ & $77.2 \%$ \\
Timdghart & $0.051 \mathrm{~km}^{2}$ & $0.366 \mathrm{~km}^{2}$ & $87.9 \%$ \\
\hline
\end{tabular}

The abandonment of the terraces can also be noted by the change in the hypsometric curve of the TAS which is more evident at the extremes of the TAS's altitudinal range (Figure 4). 


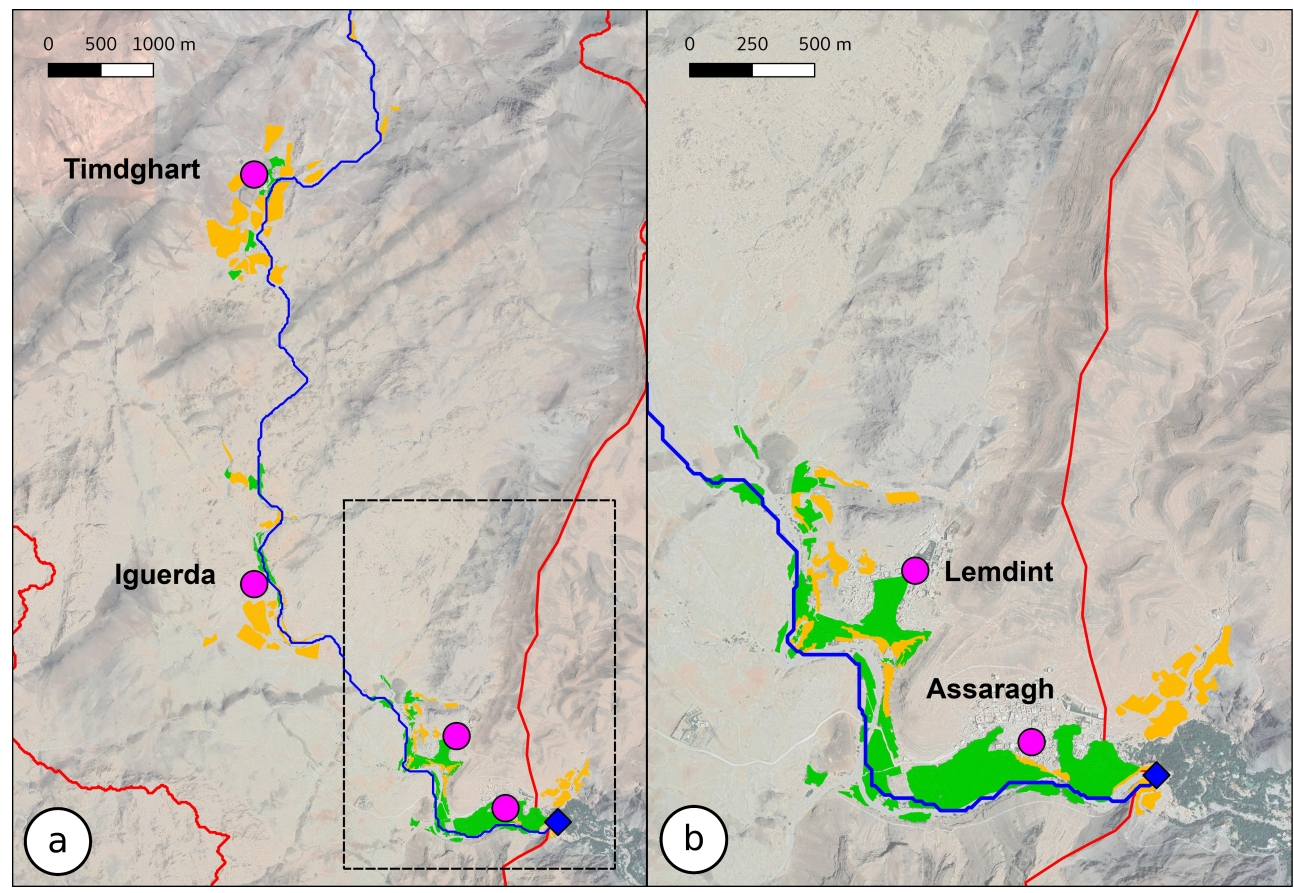

Figure 3. TAS present in the basin: in orange the abandoned terraces, in green the active terraces coinciding almost entirely with the vegetated surface, in deep blue the assif, the circles in magenta are the ksours, the diamond-shaped point in blue is the basin's outlet, called also amot and in red the watershed boundaries. (a) All the terraced systems surveyed inside the basin. (b) Focus of the Assaragh TAS, the only one still active in the basin.

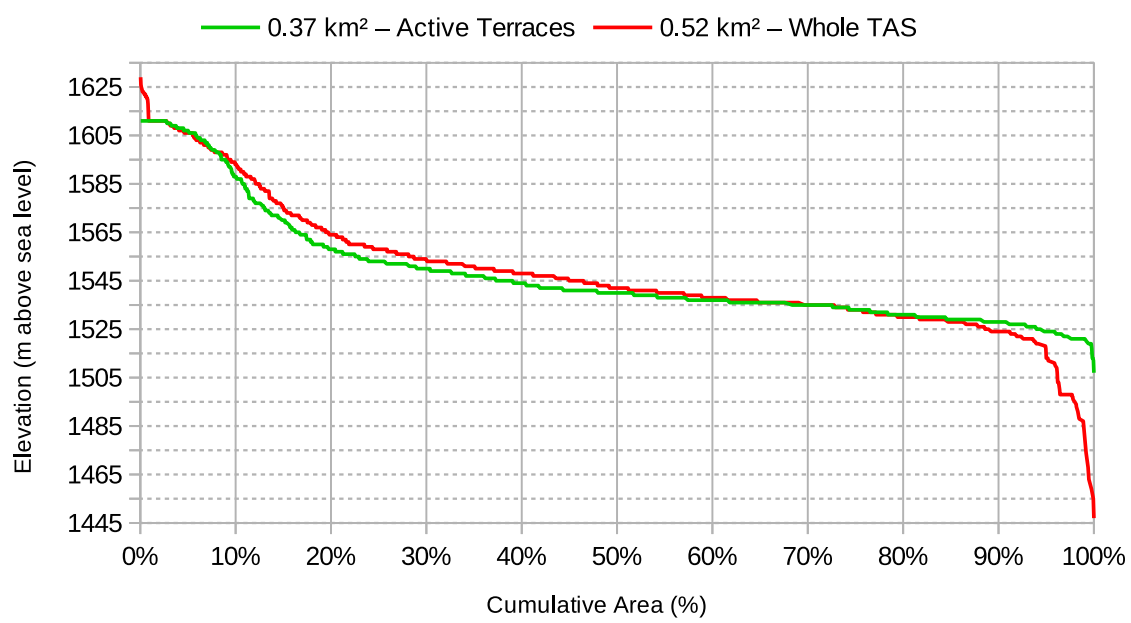

Figure 4. Comparative hypsometric curves of the cultivated terraced surface versus the whole TAS's surface accounting for cultivated and abandoned terraces.

The abandonment of the terraces is perceived by the inhabitants of the villages as an issue linked mainly to the loss of identity and landscape beauty, while the farmers who own terraces adjacent to the abandoned ones sometimes report an undergoing hydrogeological degradation of theirs. It should also be noted that the only vegetation of the basin (accounting only for $\sim 0.5 \%$ of the basin area) is present only on the cultivated or recently abandoned terraces, with very few exceptions along the course of the wadi.

For this study, the authors will consider Assragh and Lemdint as part of the same TAS, referred to, hereafter, as Assaragh TAS. As stated previously, Iguerda and Timdghart in the past had their own 
TAS which today is almost completely lost. The study is carried out at the basin scale but focuses on the Assaragh TAS.

\subsection{Conceptualization of the Case Study through SD}

\subsubsection{Definition of SD}

The study of SD suggests that an SD behavior is controlled by feedback loop structures $[46,47]$ that can provide a potentially useful conceptual framework in the assessment of non-linear complex feedbacks, such as the ones arising from a tightly coupled social-ecological system [25], for example the phenomenon of the degradation or abandonment of TAS [25]. This is achieved through casual loop diagrams (CLD), which are tools that allow the conceptualization of such structures, part of a complex system in systems thinking. A CLD is a powerful SD tool used to illustrate pictures of systemic perceptions or feedback structure patterns. CLDs consist of balancing or negative feedback loops (B), or reinforcing or positive feedback loops (R) and/or a combination of both. Defining system archetypes as a generic system structure presenting common behavioral patterns [48,49] reinforcing and balancing feedback loops are the simplest system archetypes emerging from a CLD. In real systems a combination of these basic archetypes can present more complex dynamic behaviors, which can be described by appropriate and more structured archetypes that adequately describe the emerging dynamic [49].

The advantage of SD modeling lies in its possibility of integrating quantitative and qualitative data, even if they are incomplete or of poor quality [50-53]. In addition, it is possible to analyze the SD in retrospect by corroborating hypotheses on how the system obtained its current state, despite lacking data regarding its past states [35].

\subsubsection{Modelling Process}

Modeling a complex system by means of SD can be seen as an iterative process, starting with a general conceptualization of the CLD on the basis of a selected literature review on similar cases, a general observation of the ecosystem to be modeled and experience. The first CLD conceptualization should address the data collection and analysis process. In the light of the data collected and analyzed, the robustness of the CLD can be verified and, if necessary, reformulated and enlarged to better represent the case study and the dynamics to be investigated. Again, if qualitative or quantitative data is needed to investigate some dynamics, a new data collection campaign must be carried out and consequently a new verification of the CLD. These processes are iterated until the data collected, the dynamics observed and the model represented by means of the CLD, are self-consistent. In this sense a self-consistency of the model can be seen as its validation [49]. This global process has been well illustrated by Wolstenholme [50] and bears the legacy of a methodology, such as that of SD, born in the industrial sector to map and improve production processes [46,51].

\subsubsection{Selected Literature Review on Water Resources and Ecosystems Related Problems}

In the literature, there has been several occasions where SD was employed to tackle environmental issues. In particular, Shahbazbegian et al. [31] developed a hydropolitical analysis in relation to cross-border basins (e.g., Helmand basin on Afghanistan/Iran border) keeping in account social and political drivers together with quantitative data on water volumes and flow rates, while other authors, such as Di Baldassarre et al. [33] used this approach to map and describe the reservoir paradox-discussed further in this paper-in analogy with a paradox linked to modern irrigation. Tenza et al. [32] presented a qualitative model using the conceptualization process of the SD to study the dynamics of an oasis in Mexico that has witnessed a dramatic decline in recent decades. The authors used in-depth interviews, participant observation, expert opinions and official statistical datasets to define the boundaries, and structure in a CLD of the investigated system. Martínez-Fernández et al. [30] traced the environmental and socio-economic interactions in the evolution of traditional irrigated 
lands in Murcia by means of an SD model containing the main social, economic and environmental policies set up by local and regional authorities. Sušnik et al. [34] applied SD to study the water resource management in Merguellil catchment in Tunisia, an arid catchment subjected to domestic, industrial, agricultural and external pumping and presenting multiple feedback loops connected to the over-exploitation of water resources. All of the above studies have been exemplary models on which to base the first CLD conceptualization.

\subsubsection{The Model for Assaragh Case Study}

On the basis of what is stated in the previous sections, the CLD for Assaragh case study, represented in the Figure 5, was built. Positive and negative relations between the variables in the CLD are represented. A positive relation implies positive feedback, e.g., a good recharge of the water table, therefore a wide availability of groundwater, encourages irrigation by exploiting the aquifer. A negative relation implies a negative feedback, e.g., a more pronounced irrigation deficit leads to a reduced plant growth and productivity. Note that a positive feedback loop is composed by an even number of negative relations, e.g., an increase in groundwater irrigation discourages the development of rainwater irrigation leading to its reduction, and, thus, watering using groundwater becomes increasingly necessary.

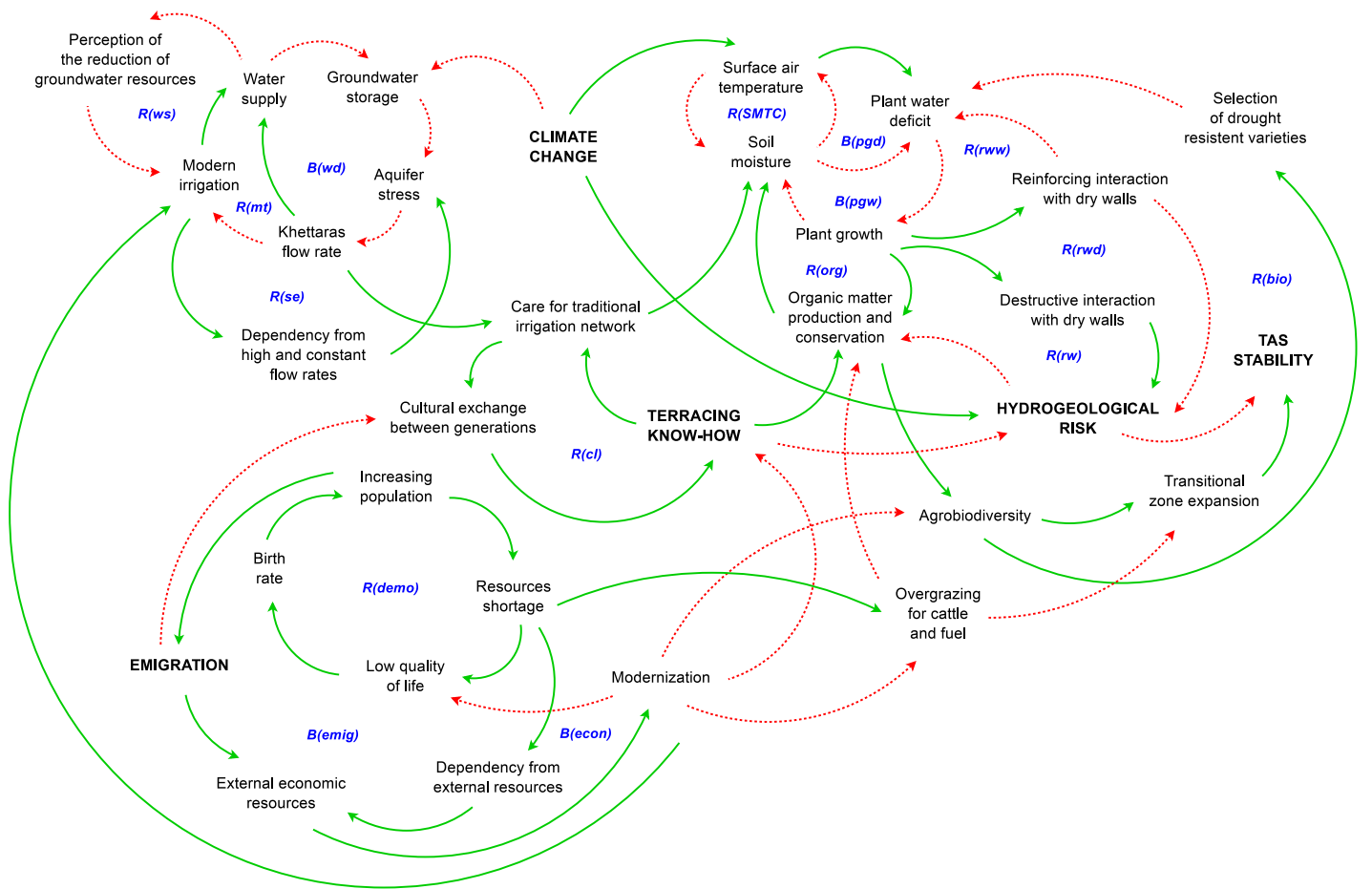

Figure 5. Map of the dynamics in Assaragh, based on system dynamics (SD). Red dotted lines represent negative coupling, e.g., an increase in emigration implies a decrease in cultural exchange between generations. Green lines represent positive coupling, e.g., an increase in cultural exchange between generations increases the know-how retention inside the village in relation to terracing and dry walling. Feedback loops are noted in blue (see glossary in Appendix A for some terms).

The mapped causal loops are linked in the diagram with five main variables: climate change, terracing know-how, emigration, hydrogeological risk and TAS stability. The main variables have been identified on the basis of three principles: they can be megatrends that occur on a global scale, they are variables that generally occur in similar case studies or they are elements characterizing the class of problems analyzed in the case study. In order to properly address the data collection and analysis a study of the archetypical structures of the CLD is needed $[35,46,50]$. Feedback loops are listed and briefly described below, in Table 3, for the sake of simplicity; those borrowed from similar problems 
are subsequently discussed in relation to the original problem considered in the bibliographic analysis during the construction of the CLD.

Table 3. Description of loops from Figure 5.

\begin{tabular}{|c|c|c|}
\hline Water supply & $R(w s):$ & $\begin{array}{l}\text { Modern irrigation increases water withdrawal capability and flexibility, } \\
\text { increasing Water supply that can mislead the Perception of the reduction } \\
\text { of groundwater resources and thus, encouraging a shift towards Modern } \\
\text { irrigation to increase groundwater exploitation. }\end{array}$ \\
\hline Water demand & $B(w d)$ & $\begin{array}{l}\text { An Aquifer stress can reduce the Khettaras flow rate which governs Water } \\
\text { supply; a reduction in Water supply can increase Groundwater storage, } \\
\text { easing the Aquifer stress, increasing Khettaras flow rate. }\end{array}$ \\
\hline Traditional irrigation drift & $R(m t)$ & $\begin{array}{l}\text { Khettaras flow rate decreases, encouraging a drift towards Modern irrigation } \\
\text { systems which increases Water supply, thus, reducing Groundwater storage, } \\
\text { which cause the increase of Aquifer stress, reducing the Khettaras flow rate. }\end{array}$ \\
\hline Supply effect & $\mathrm{R}(\mathrm{se})$ & $\begin{array}{l}\text { Modern irrigation generally creates Dependency from high and constant flow } \\
\text { rates increasing Aquifer stress, which by reducing even more the Khettaras } \\
\text { flow rate increases dependency from Modern irrigation. }\end{array}$ \\
\hline Demographic loop & $R($ demo) & $\begin{array}{l}\text { Increasing population leads to a Resources shortage, which implies a Low } \\
\text { quality of life, leading to a Birth rate increase. }\end{array}$ \\
\hline Emigration loop & B(emig) & $\begin{array}{l}\text { Emigration leads to an increase of emigrants sending money back to their } \\
\text { families increasing External economic resources used to start a Modernization } \\
\text { process inside the village, improving the Low quality of life. Higher quality } \\
\text { of life reduces the Birth rate, reducing the Increasing population. }\end{array}$ \\
\hline Economic dependency loop & B(econ) & $\begin{array}{l}\text { External economic resources initiates a Modernization process inside the } \\
\text { village improving the Low quality of life. Higher quality of life reduces the } \\
\text { Birth rate, reducing the Increasing population, thus, reducing the Resources } \\
\text { shortage and accordingly the Dependency from External economic resources. }\end{array}$ \\
\hline Cultural landscape loop & $\mathrm{R}(\mathrm{cl})$ & $\begin{array}{l}\text { TERRACING KNOW-HOW leads to a better Care for traditional irrigation } \\
\text { network allowing a creation for a cultural landscape, that facilitates a Cultural } \\
\text { exchange between generations. }\end{array}$ \\
\hline Soil moisture and temp. & R(SMTC) & $\begin{array}{l}\text { An increase in Soil moisture implies a decrease in Surface air temperature } \\
\text { and vice versa. }\end{array}$ \\
\hline Plant growth—wet lim. & $B(p g w)$ & $\begin{array}{l}\text { Plant growth decreases Soil moisture, which increases Plant water deficit } \\
\text { which limits Plant growth. }\end{array}$ \\
\hline Plant growth—dry lim. & $B(p g d)$ & $\begin{array}{l}\text { Plant growth decreases Soil moisture, which decreases Surface air } \\
\text { temperature which, by increasing potential evapotranspiration, increases } \\
\text { Plant water deficit which limits Plant growth. }\end{array}$ \\
\hline Roots reinf. walls-wet loop & $R(r w w)$ & $\begin{array}{l}\text { Plant growth can present a Reinforcing interaction with dry walls by the } \\
\text { consolidation effect exerted by roots; this interaction shades the wall from } \\
\text { wind and solar radiation, and the compaction of the stones reduces water } \\
\text { runoff; all these effects decrease Plant water deficit promoting Plant growth. }\end{array}$ \\
\hline Roots reinf. walls—dry loop & $\mathrm{R}(\mathrm{rwd})$ & $\begin{array}{l}\text { Plant growth can present a Reinforcing interaction with dry walls through } \\
\text { the consolidation effect exerted by roots; this interaction decreases } \\
\text { HYDROGEOLOGICAL RISK, which generally increases the organic matter } \\
\text { flushout. An increase in Organic matter production and conservation } \\
\text { promotes Soil moisture which reduces Plant water deficit promoting Plant } \\
\text { growth. }\end{array}$ \\
\hline Roots disrupting walls & $\mathrm{B}(\mathrm{rw})$ & $\begin{array}{l}\text { Plant growth can present a Destructive interaction with dry walls } \\
\text { by the consolidation effect exerted by roots, this interaction increases } \\
\text { HYDROGEOLOGICAL RISK, which generally decreases the organic matter } \\
\text { flushout. An increase in Organic matter production and conservation } \\
\text { promotes Soil moisture which reduces Plant water deficit promoting Plant } \\
\text { growth. }\end{array}$ \\
\hline Drought adaptation & R(bio) & $\begin{array}{l}\text { An increase in Agrobiodiversity favors the Selection of drought resistant } \\
\text { varieties, which can lead to a reduction of Plant water deficit, thus, to a } \\
\text { promotion of Plant growth, which implies an increase in Organic matter } \\
\text { production and conservation necessary to develop a higher Agrobiodiversity. }\end{array}$ \\
\hline
\end{tabular}

The causal loops $\mathrm{B}(\mathrm{emig}), \mathrm{R}(\mathrm{demo})$ and $\mathrm{B}(\mathrm{econ})$ have been mapped according to a quite complete study by Silverstein [54] investigating the emigration phenomenon in the specific case of Amazigh oases in North Africa. These three loops together create an archetype addressed by the main variable of emigration, discussed further in the result Section 3.5. The causal loop of agrobiodiversity and 
organic matter production and conservation has been mapped with reference to three studies; the first one [55] was on carbon sequestration in arid ecosystems, the second one [56] on how genetic erosion impedes adaptive responses to stressful environments, and by consequence a loss in biodiversity and resiliency and the third [57] on the importance of a transitional zone between desert and TAS in order to maintain TAS's stability and allowing dynamics on natural selection [58,59] for species fitter to arid climates.

Loops including plant growth and interaction with dry walls, as well as the R(SMTC) loop, have been mapped starting from direct field observation and from studies of various authors such as Castelli et al. [60] and Tarolli et al. [12]. The archetype emerging around the main variables (climate change, terracing know-how and hydrogeological risk) directly influences the TAS's stability. However, it does not give a priori a causal relation between climate change and TAS's degradation, and this is what will be further investigated in the data collection section.

The loop $\mathrm{R}(\mathrm{cl})$ on cultural landscapes refers directly to the vast literature promoted by UNESCO on the theme; in particular, for traditional water harvesting techniques and water distribution can be referred to a study of Barontini et al. [20]. The loops $R(w s), R(m t), B(w d)$ and $R($ se) have been mapped to describe a dynamic that emerged during the second phase of the modelling process, after a first field survey. These loops creates a more complex archetype analogous to the one studied by Di Baldassarre et al. [33] in relation to the reservoir paradox discussed later in Section 3.4 of the results.

\subsection{Data Collection}

The Assaragh watershed is well-mapped from a lithological and geological point of view. However, meteorological, climatic and hydrological data as well as precise data on the state of the aquifers are missing. With regards to the availability of socio-economic data, the detailed demographic information of the censuses prior to that of 2014 does not capture the details of the local scale. Missing data was complemented by direct field collection and freely accessible databases.

As stated previously, an SD approach allows to integrate qualitative and quantitative data. In the present case study the data collection process has been subdivided into three phases. A first phase was established including field studies, as well as unstructured data collection through direct observation, photographic documentation and informal interviews with the inhabitants. A second phase followed, including the collection of terrain data (Digital Elevation Model-DEM dowloaded from NASAEarth [61]), satellite imagery, climatic and socio-economic data.

The third and final phase - entirely affected by the Covid-19 pandemic-should have involved the distribution of questionnaires on the perception of risk and a mapping on the field of agro-biodiversity. This phase was conducted remotely via telephone instructions, remote surveys through photographs and videos thanks to the help of young people from the oasis. The data collected in the third phase have been used, despite the fact that it was not up-to-standards, since the questionnaires were not administered through a re-entry protocol and some responses were influenced by the previous interviews. However, this data provided more organized and structured additional information compared to that found in the first phase. Needless to say, third phase data were treated with much discretion in relation to what was already observed and documented during the first phase.

\subsubsection{Field Surveys and Unstructured Data Collection}

Two field surveys, one in May 2019 and one during the end of October and the beginning of November 2019, have been vital for the documentation of the terraces' status, the irrigation network and the agricultural practices (Figures 6-8, Figures A1-A3). The structure of the terraces and the interaction of roots with dry walls, the building techniques and the consequences of flood events and their magnitude have been investigated, as well. 

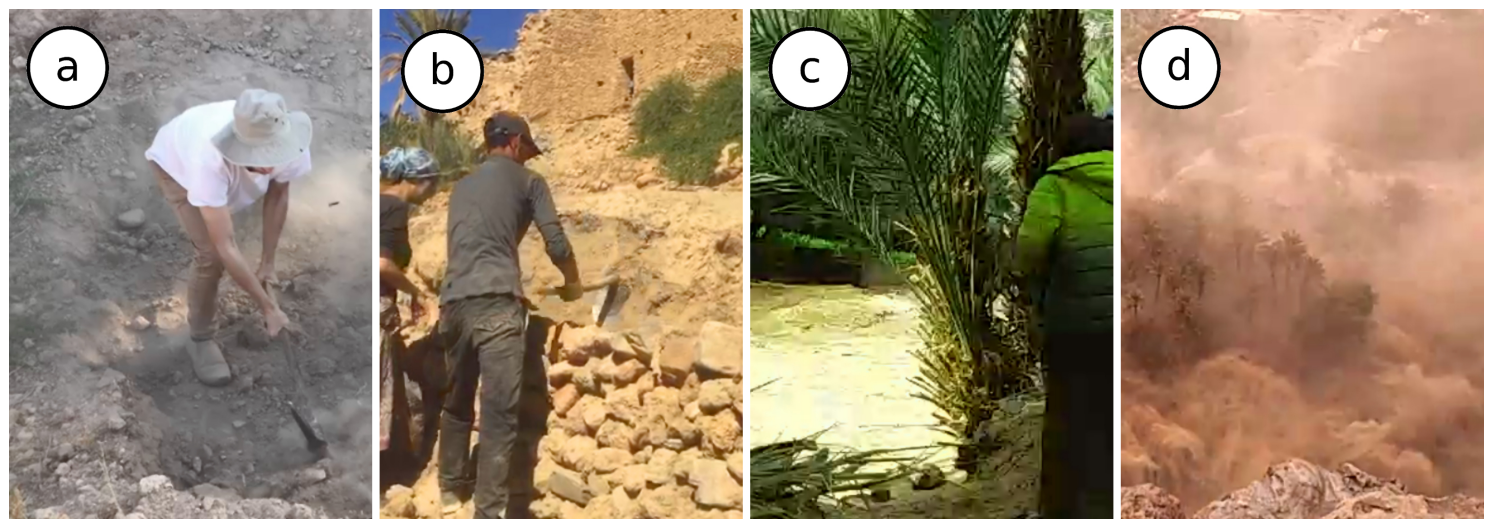

Figure 6. Field surveys and direct observation: (a) observation of the granulometry, type of rocks and roots effect on collapsed terraces. (b) Description of the local building techniques; farmers were asked to rebuild a collapsed terrace. (c) From videos taken by the inhabitants during the flood, the wet section and flow velocity in some sections of the wadi, have been estimated. (d) Excerpt from a video documenting the flood effect at the basin's outlet.

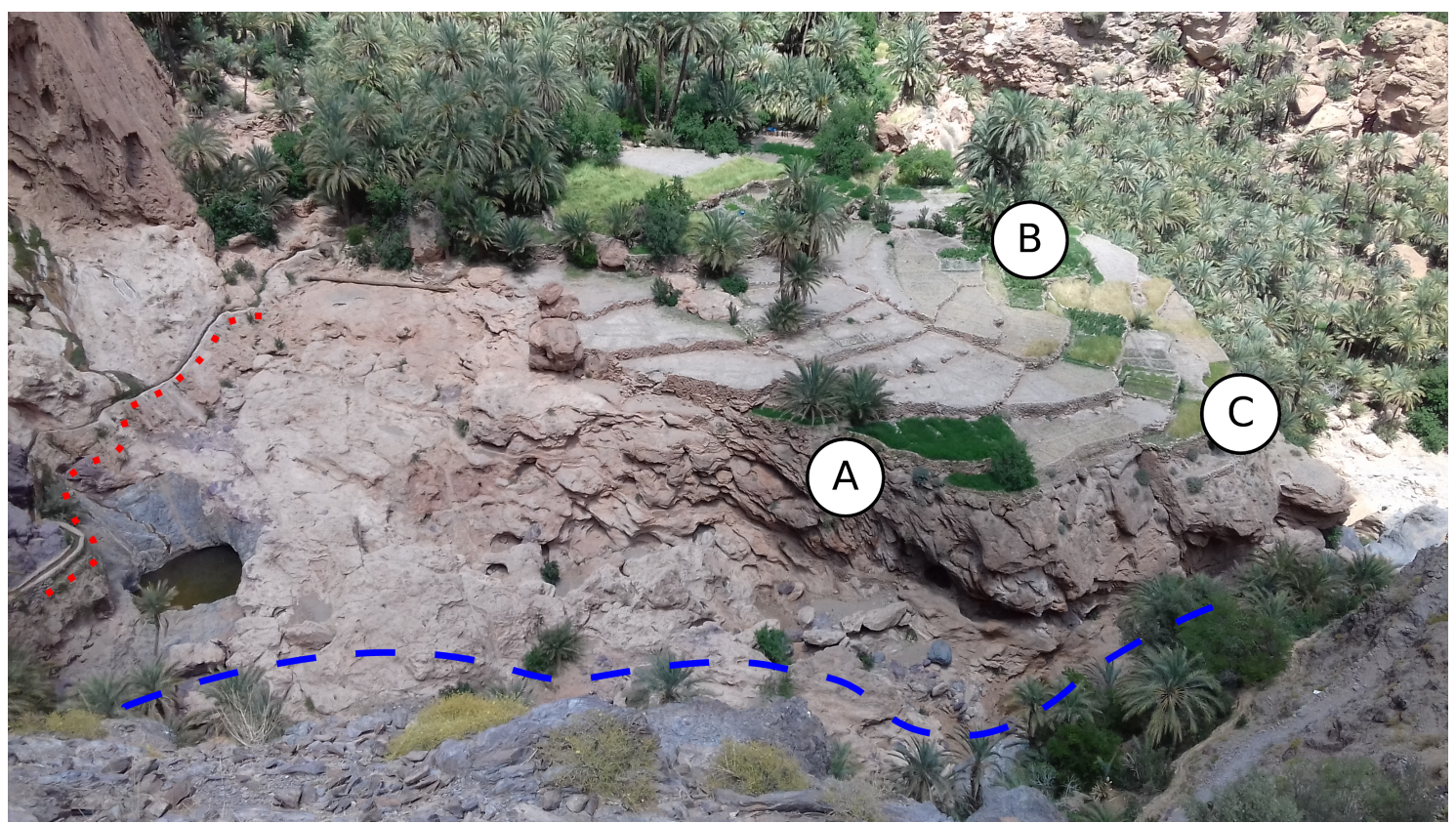

Figure 7. Overview of some plots in Assaragh TAS. Dotted red line: traditional irrigation channel.

Dashed blue line: main natural wadi stream. Cultivated plots: (A) alfalfa, (B) faba bean, (C) wheat.

The ground survey was necessary as some plowed plots can easily be confused with abandoned plots when using only satellite imagery. Furthermore, in the basin some sedimentary concentric formations are present, that can easily be confused with abandoned terraces (Figure 9). The surveyed abandoned terraces were outlined in GIS software using Google satellite imagery as the basis.

\subsubsection{Terrain, Meteorological and Demographic Data}

Terrain data were available in the form of a DEM with a resolution of $5 \mathrm{~m}$ (NASAEarth [61]) and Landsat satellite imagery. Climatic satellite data (monthly temperature and precipitation from 1982 to 2019) were retrieved from NASA Power database [62] with a resolution of $0.5^{\circ}$. This validated data regards all of Africa and are the product of interpolation (using the MERRA-2 algorithm) of multiple sources of measurements both from satellite and from land surface. It can provide quite reliable results [63] and, therefore, it was overall preferred. It should be mentioned that the closest weather and climatic stations, as the crow flies to Assaragh, are located in Taliouine $(65 \mathrm{~km})$ and Ouarzazate 
$(110 \mathrm{~km})$. Both cities have different climatic regimes and altitudes in respect to the investigated basin. For demography the census data, freely available from governmental sources [64], has been used.

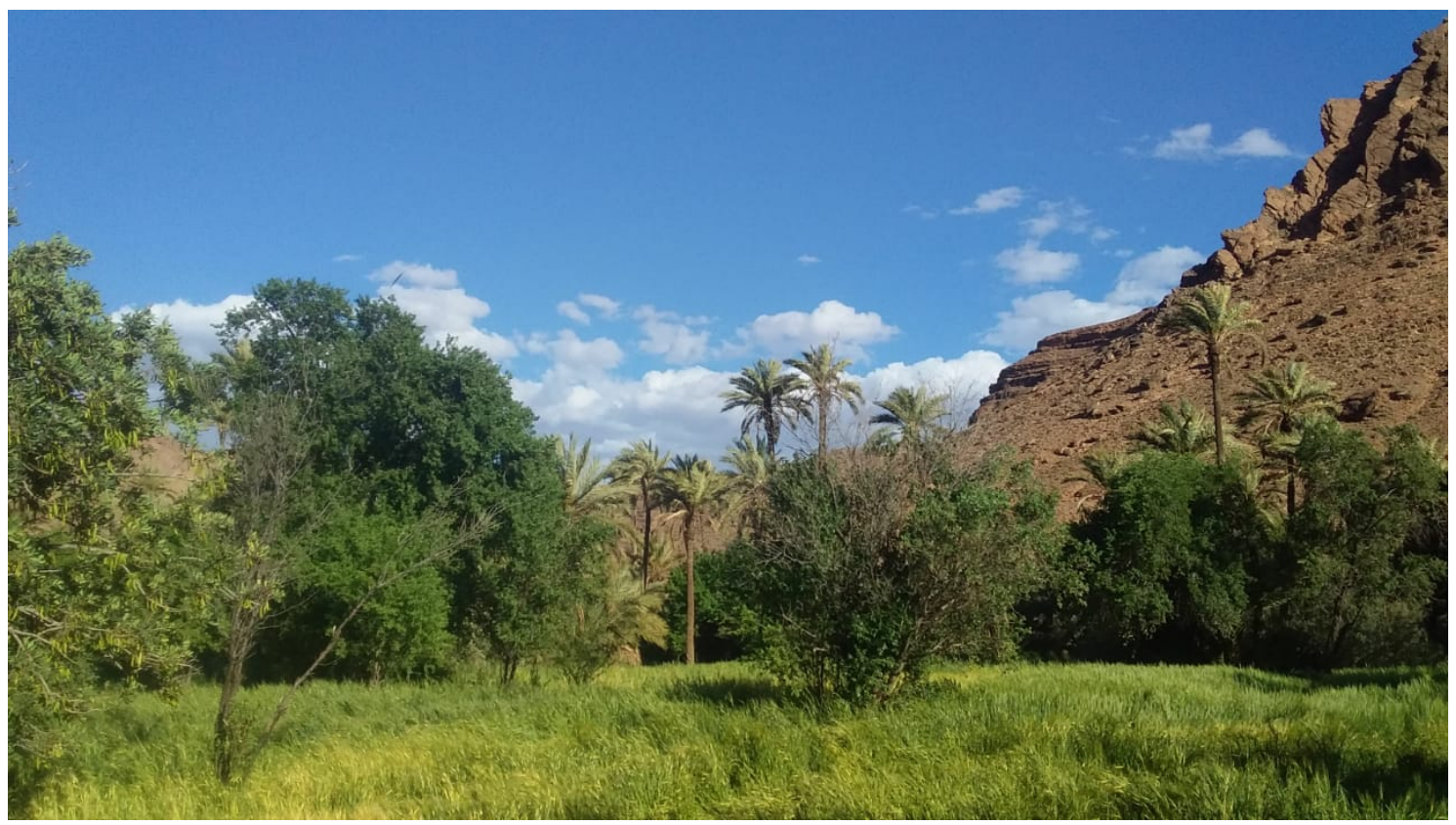

Figure 8. Example of cultural practice with date palm, fruit trees (olive, carob and pomegranate) and wheat, planted in the same plot.

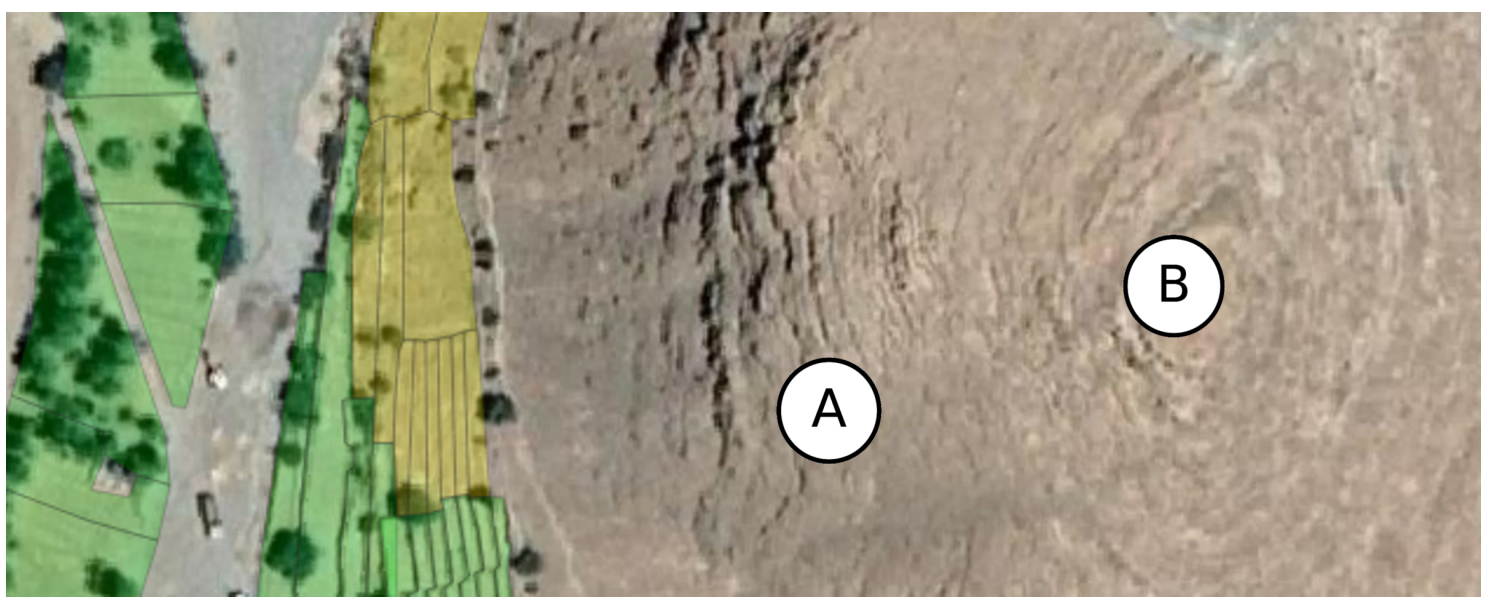

Figure 9. Terraces detected in GIS software by hand with satellite imagery from Google as basis. A previous field survey was already carried out. Some concentric geological formations (A) with center in (B), which can be easily mistaken for abandoned terraces.

\subsubsection{Structured Data Collection}

The structured data collection regarded a questionnaire divided into three parts; a first part questioning the farmers, required a integer estimate on the occurrence of some phenomena in recent years and in the past (Table A3), a second part included statements measured on Likert scale (1-5), see Table A4 and a third and final part aimed at detecting the cultivated plant species and the agricultural techniques practiced, by means of a presence matrix (Section 2.4.5). The respondents were 15 farmers ranging in age from 41 to 75 years old. The interviews were administered by a local active citizen from Assaragh who supported the process of field surveys. 


\subsection{Data Analysis}

\subsubsection{Geological Data}

In Assaragh basin, the lithological formations, presented in Figure 10, can be subdivided into three categories as summarized in Table 4. The central Anti-Atlas is characterized by the absence of generalized regional aquifers; however, at the level of the Assaragh basin, the lithological shelters shared circulations between the karsts and the fractures as shown in Table 4 . The highly developed Adoudounian limestone series in the basin at high altitudes (basin's North), can constitute a water reservoir if the underlying substrate is impermeable. It favors a strong runoff towards the amot (wadi's outlet) of the basin by following the watercourses and it can participate in the recharging of the perched aquifers by following the plants of the strike-slip faults and vertical faults, abundant in the center of the basin. Generally speaking, most of the basin is made up of hard rocks and non-permeable soils which cause high runoff. The latter adds to the effect of slopes and amplifies the erosive process $[65,66]$ by digging ravines in the soil and causing the abandonment of the terraces or even their destruction. Towards low-lying areas, the concentration of rainwater slightly increases infiltration along the alluvial valleys due to the lithological nature. The water follows the cracks (transcurrent faults and vertical faults; see Figure 10) and forms underground micro-conduits, getting distributed in the deep areas. Therefore a weak erosive process is present which can maintain the durability of TAS. However, the infiltrated volume most likely remains much lower compared to the precipitation volume; therefore high runoff dominates in the basin, especially during stormy periods.

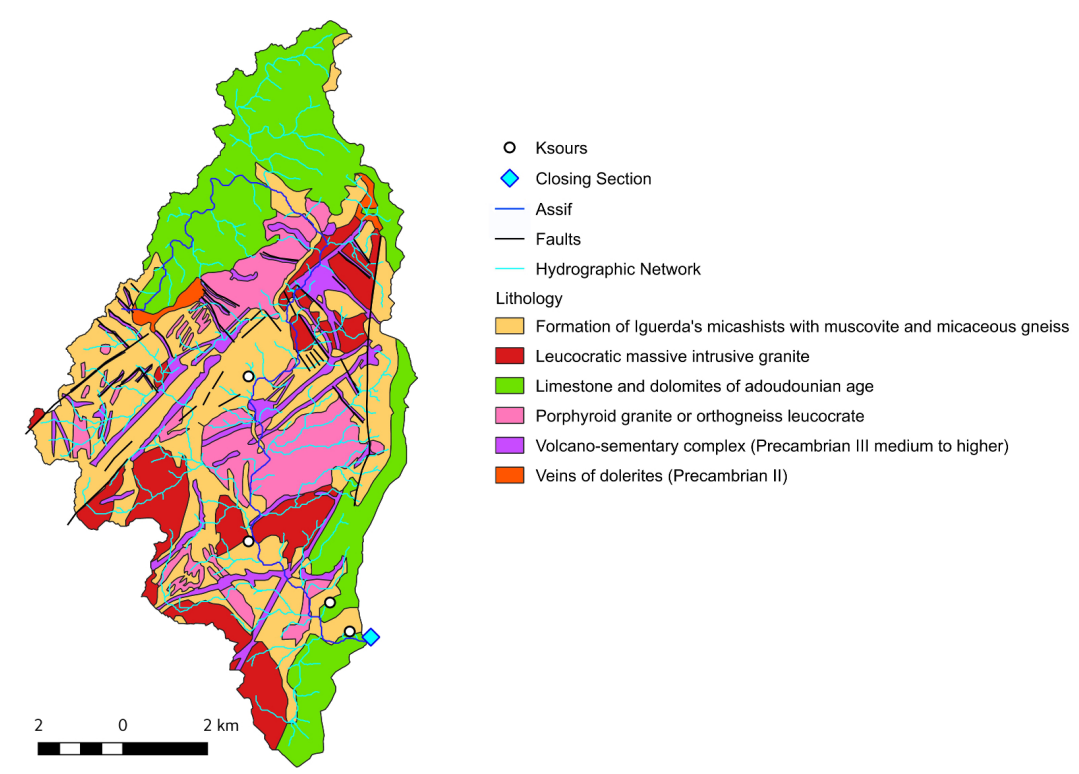

Figure 10. Geological map of the Assaragh watershed extracted from the geological map of Agadir-Melloul available at the 1/100,000 scale (Faure-Muret et al. 1992 [67]).

Table 4. Hydrogeological classes of the investigated area.

\begin{tabular}{cccc}
\hline Hydrogeological Class & Fracturing & Lithology & $\%$ \\
\hline Land with deep karst circulation & Abundant & Micaschists and gneiss from Iguerda's buttonhole & $35.6 \%$ \\
Hyporheic circulation in wadis and valleys & Uncommon & Plio-quaternary deposits, volcano-sedimentary complex & $27.3 \%$ \\
Impermeable or less permeable grounds & Absent & Adoudonian limestones, granites and orthogneiss & $37.1 \%$ \\
\hline
\end{tabular}




\subsubsection{Climatic Data}

Using the 37-year monthly meteorological data of NASA Power, the periods consisting of consecutive days without rain have been identified. From the analysis, five out of six periods of longer duration fall within the second half of the 37-year interval emerged, as summarized in Table 5 .

Table 5. Six of the longest periods of consecutive days without rain. These periods are extracted from NASA Power dataset for daily precipitation from 1982 to 2019.

\begin{tabular}{ccc}
\hline Year & Duration in Days & Last Day without Rain \\
\hline 2005 & 55 & $5 \mathrm{May}$ \\
1992 & 44 & $29 \mathrm{Jan}$ \\
2007 & 42 & $7 \mathrm{Jul}$ \\
2019 & 40 & $22 \mathrm{Jul}$ \\
2002 & 39 & $4 \mathrm{Jul}$ \\
2017 & 38 & $25 \mathrm{Nov}$ \\
\hline
\end{tabular}

A fractal analysis of wet and dry periods was carried out according to the methodology developed by Bazuhair et al. [68]. The results show a pattern of a semi-arid climate with similar duration for dry and wet periods of short durations and dry periods that are generally shorter but more persistent (Figure 11).

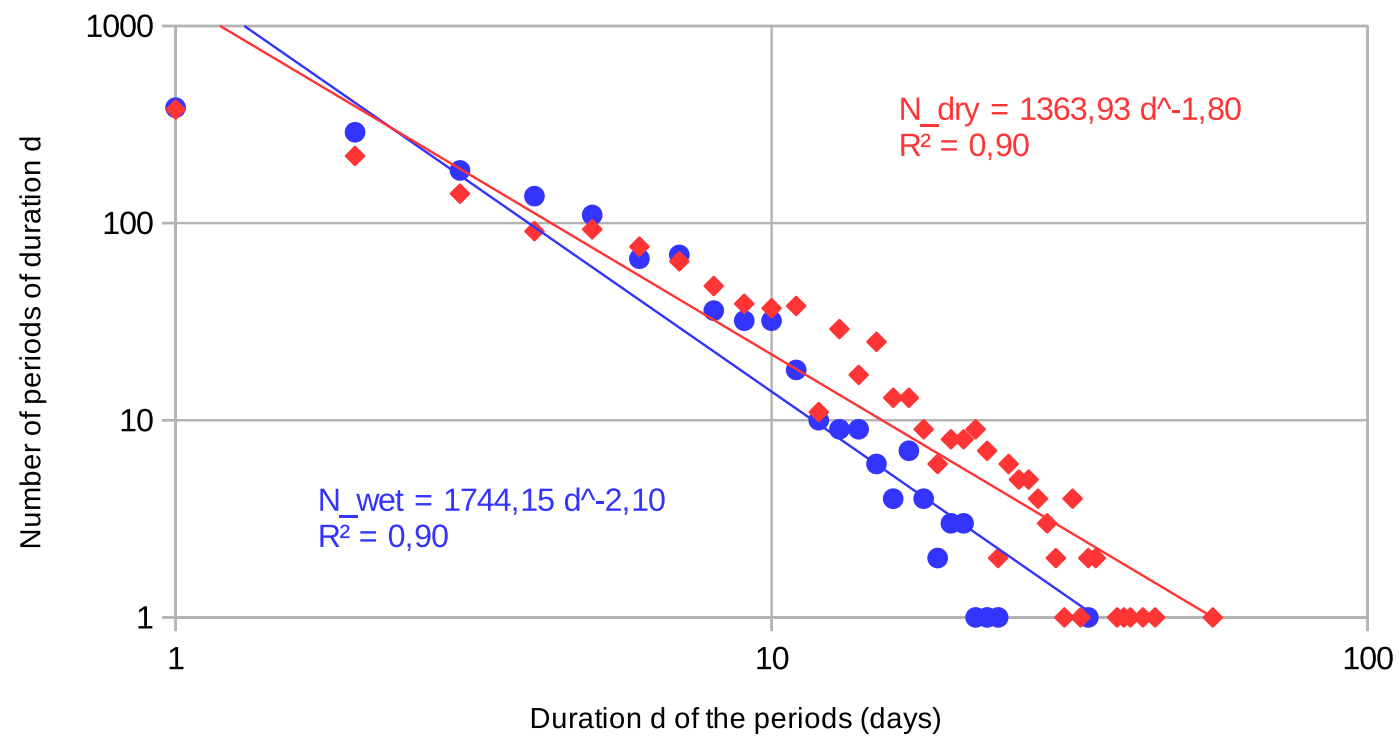

Figure 11. Fractal analysis of wet (in blue) and dry (in red) periods performed on the NASA Power dataset for daily precipitation from 1982 to 2019.

The results of this analysis are confirmed by the data collected from unstructured interviews and questionnaires. The 15 interviewed farmers agreed on a halvening of rainy days in the past 30 years and on an approximate reduction of three to four times the rainy days in the past 60 years (see Table A3); in general, there is a complete agreement regarding the reduction of rainy days with respect to the past.

\subsubsection{Water Resources Balance}

In the present case study, regionalization methods for the estimation of parameters used in rainfall-runoff models were not applicable, since the basin is extremely small compared to the 
dimensions of the well-studied wadi basins [69]. Therefore, a parsimonious models and reasonable hypothesis based on common sense, literature and experience have been adopted.

As one can observe from Figure 12 the investigated basin has a wet season that develops from November to March in which it rains just over $65 \%(\sim 150 \mathrm{~mm})$ of the annual precipitation. Starting from this satellite meteorological data, an estimation of the actual and potential evaporation and of the monthly water deficit within the basin according to the Thornthwaite method was carried out [70].

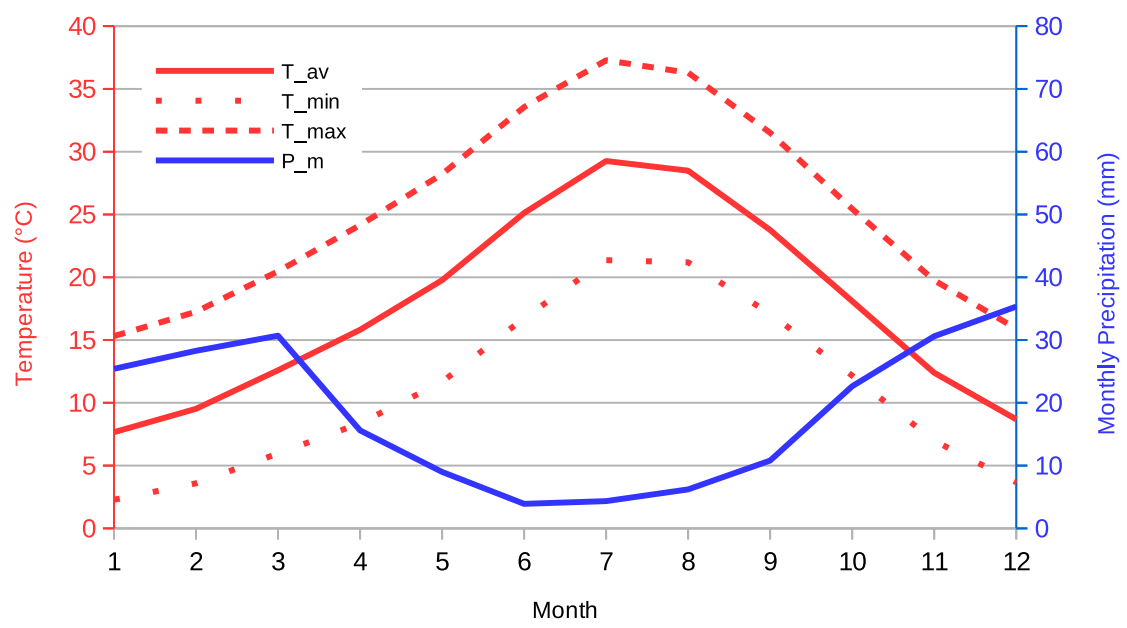

Figure 12. Climograph at Assaragh derived from the NASA Power dataset of monthly temperatures and precipitations from 1984 to 2013.

According to Thornthwaite, an estimate of the hydrological balance of the agricultural land in the TAS, has been developed, assuming a specific water capacity retained by the soil as $U=50 \mathrm{~mm}$. This estimate was conservative and defined on the basis of experience and field observations (small plots in terraces, flooded and often surrounded and shaded by trees with deep root systems; some example images can be seen in Figure 13).
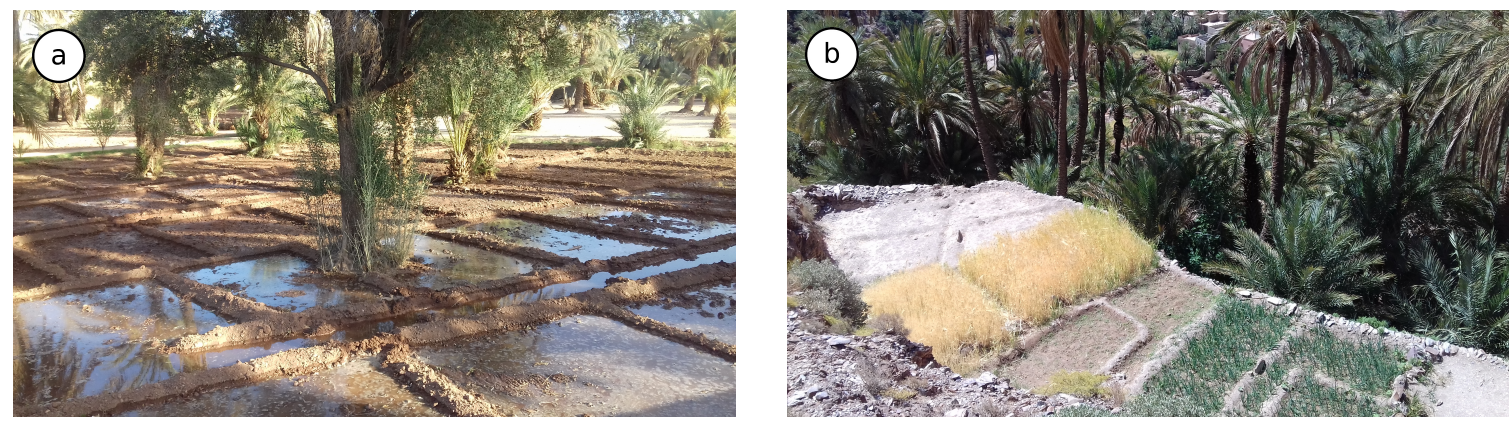

Figure 13. Traditional agricultural management in TAS: (a) flood irrigation of cultivated plots shaded by palms and other arboreal cultures. (b) Terrace subdivided in plots cultivated with different crops and vegetables.

The general law for soil desiccation [71] during the dry season is given by:

$$
-\frac{d(P-E)}{d\left(P-E_{p}\right)}=\left(\frac{A}{U}\right)^{m} \quad m \geq 0
$$

where $P$ is the precipitation, $E$ the actual evapotranspiration, $E_{p}$ the potential evapotranspiration, $A$ the specific volume of water in the soil volume affected by evapotranspiration, varying from 0 if completely dry to $U$ if soaked. 
Since there was no possibility to study the soil desiccation dynamics in the basin, three soil desiccation laws were hypothesized, for $m=0,1$ and 2. Then, using Equation (1), the hydrological balance for the agricultural soil on a monthly scale was developed, obtaining the results shown in Figure 14.

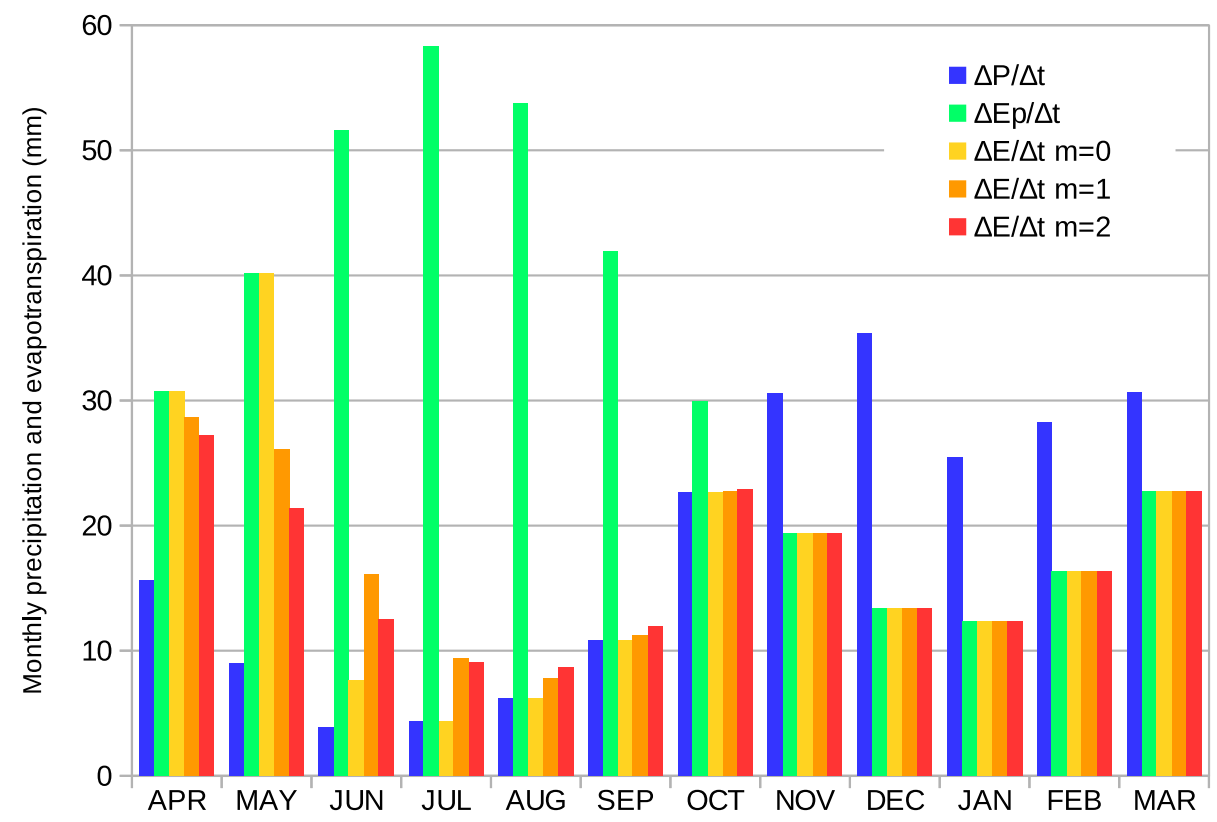

Figure 14. Hydrological balance for agricultural soil according to Thornthwaite. Three soil dissecation laws were considered according to Equation (1) for $m=0,1,2$. Derived from NASA Power dataset of monthly temperatures and precipitations from 1984 to 2013.

Water deficit and surplus values and ratios illustrated in Figure 14 have been summarized in Table 6. One can note that agricultural soil suffers from a quite high water deficit in dry season. However, this deficit is not representative of the operation of the TAS as it is compensated by irrigation from the aquifer, which is recharged by rainfall over the entire basin area.

Table 6. Summary of agricultural water deficit and surplus in the basin for $m=1$.

\begin{tabular}{cc}
\hline Parameter & Value \\
\hline Cumulated precipitation in wet season & $150 \mathrm{~mm}$ \\
Cumulated precipitation in dry season & $72 \mathrm{~mm}$ \\
Cumulated potential evapotranspiration in wet season & $84 \mathrm{~mm}$ \\
Cumulated potential evapotranspiration in dry season & $306 \mathrm{~mm}$ \\
Ratio cumulated $P$ during wet season over yearly cumulated $P$ & $67 \%$ \\
Ratio cumulated $E_{p}$ during dry season over yearly cumulated $E_{p}$ & $78 \%$ \\
Water surplus in wet season & $66 \mathrm{~mm}$ \\
Water deficit in dry season & $-234 \mathrm{~mm}$ \\
\hline
\end{tabular}

Assuming the parameters shown in Table 7, and maintaining a conservative approach, the values in Table 8 were derived. Some values such as the percentage of the precipitation lost in direct evaporation and from base flow and direct runoff were just conservative estimates based on a study from De Jong et al. [72]. The authors calculated a yearly water balance for Ifre basin, which is colder, one order of magnitude larger and with higher altitudes with respect to Assaragh case study. For the Ifre basin a yearly loss for evapotranspiration equal to $74.8 \%$ of the cumulated precipitation has 
been estimated, and an outflow equal to $12.9 \%$ of the cumulated precipitation has been measured. For Assaragh basin it was estimated that $90 \%$ of the rainfall is lost by direct evaporation from bare soil in the dry season. This value is quite reasonable, since the cumulated monthly precipitation is given by relatively short rainfall events, which are not capable of soaking the dry bare soil for more than few centimetres.

Table 7. Parameters calculated and assumed to derive a water balance at the basin scale.

\begin{tabular}{cc}
\hline Parameter & Value \\
\hline Cultivated area (active terraces) & $0.474 \mathrm{~km}^{2}$ \\
Whole terraced area (active and abandoned terraces) & $1.184 \mathrm{~km}^{2}$ \\
Direct evaporation from bare soil in wet season & $65 \%$ \\
Direct evaporation from bare soil in dry season & $90 \%$ \\
Base flow plus runoff in wet season & $25 \%$ \\
Base flow plus runoff in dry season & $0 \%$ \\
Domestic water need per inhabitant & $200 \mathrm{~L} / \mathrm{in}$ \\
Number of equivalent inhabitants (animals and people) & $1500 \mathrm{in}$ \\
\hline
\end{tabular}

As shown in Table 8, under the working hypotesis previously illustrated, the Assasargh TAS presents a water surplus even during dry season and for two different scenarios, namely for the current cultivated surface $\left(0.474 \mathrm{~km}^{2}\right)$ and a hypothetical state in which abandoned terraces are cultivated, as well $\left(1.184 \mathrm{~km}^{2}\right)$.

In fact, the unstructured interviews and questionnaires have shown that despite a clear perception of the reduction in rainy days and an average increase in temperature, a reduction in the availability of the water resources, used in agriculture, is not perceived (see Table A4).

Table 8. Summary of agricultural and domestic water volumes, and water availability at the basin scale. Volumes are calculated for the current state (c. s.) considering a cultivated surface of $0.474 \mathrm{~km}^{2}$, and for a hypothetical state (h. s.) in which also abandoned terraces are cultivated for a total of $1.184 \mathrm{~km}^{2}$ of cultivated surface. See Table 2 for details. Water volumes are expressed in $10^{6} \mathrm{~m}^{3}$.

\begin{tabular}{ccc}
\hline Parameter & Absolute c. s. $\mathbf{1 0}^{\mathbf{6}} \mathbf{~ m}^{\mathbf{3}}$ & Absolute $\mathbf{~} . \mathbf{~ s . ~} \mathbf{1 0}^{\mathbf{6}} \mathbf{~ m}^{\mathbf{3}}$ \\
\hline Volume of water available during wet season & 1.305 & 1.305 \\
Volume of water available during dry season & 0.626 & 0.626 \\
Volume of water needed in agriculture during wet season & 0.040 & 0.099 \\
Volume of water needed in agriculture during dry season & 0.145 & 0.362 \\
Water surplus in wet season & 1.265 & 1.206 \\
Water surplus in dry season & 0.481 & 0.264 \\
Domestic water supply for 1500 inhabitants, in wet season & 0.064 & 0.064 \\
Domestic water supply for 1500 inhabitants, in dry season & 0.046 & 0.046 \\
\hline
\end{tabular}

\subsubsection{Demographic Data}

Morocco today is a growing country with a birth rate of 2.3 and in the past 60 years it has seen its population triple. Despite not having accurate historical census data on a basin scale, it was possible to estimate little more than a doubling of the population within the basin in the same period. The estimate was made through interviews with people from the village.

The current population in the investigated area is reported in Table 9. The demographic pyramid for Assaragh and Lemdint has been detailed in Figure 15 and by means of unstructured and structured (see Table A4) interviews and demographic data a strong and recent emigration, especially of the young male population, was observed. 
Table 9. Data from the census of 2014 (RGPH 2014 [64]). More details about the occupation structare are available in the Table A1.

\begin{tabular}{ccccc}
\hline Ksour & Female Population & Male Population & Tot. Population & Number of Households \\
\hline Assaragh \& Lemdint & $390(55.63 \%)$ & $311(44.87 \%)$ & 701 & 146 \\
Iguerda & $147(50.87 \%)$ & $142(49.13 \%)$ & 289 & 48 \\
Timdghart & $179(52.65 \%)$ & $161(47.35 \%)$ & 340 & 64 \\
\hline
\end{tabular}

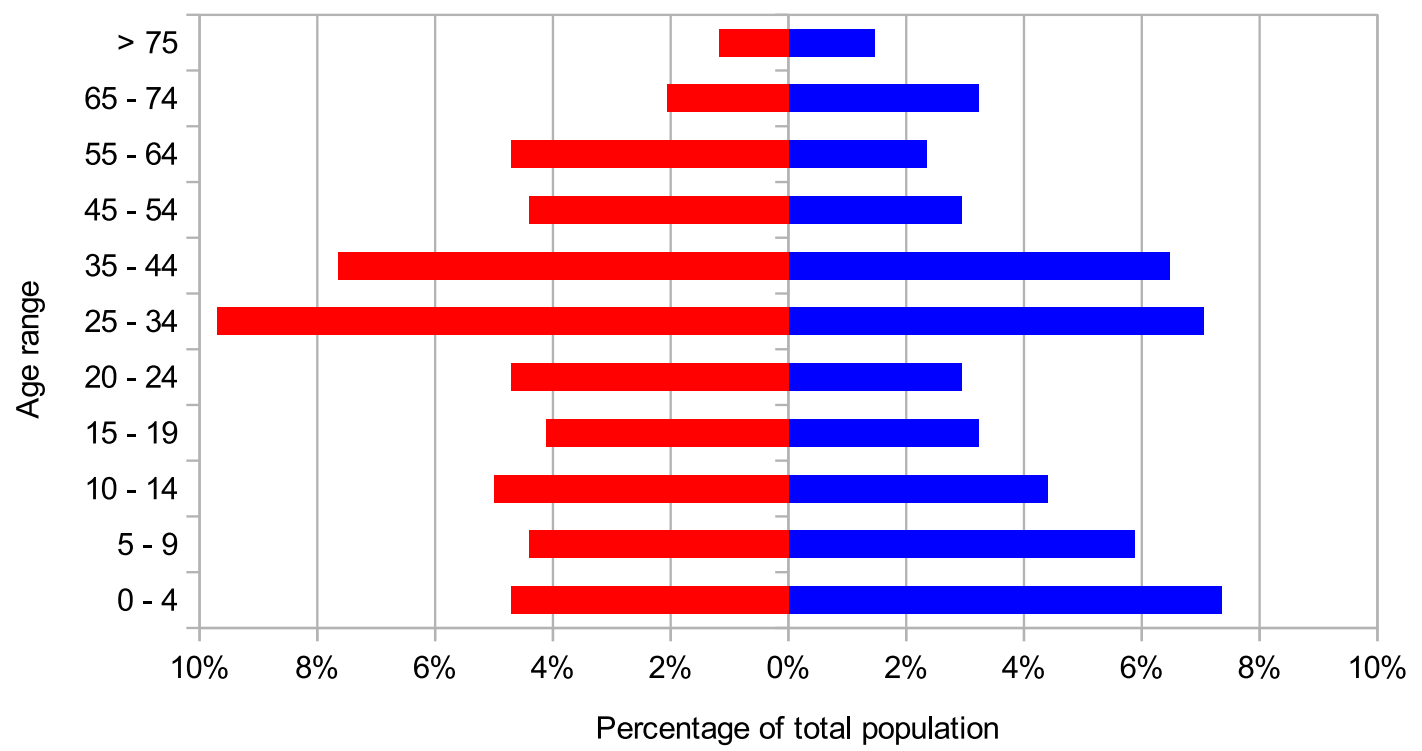

Figure 15. Demographic pyramid for Assaragh and Lemdint (RGPH 2014 [64]); total population 701 inhabitants. Left (red) the female population, right (blue) the male population.

What emerged from these interviews and questionnaires was a perception of terraces abandonment as an issue for the village although there is an impression of a global improvement in the quality of life in Assaragh, probably also thanks to some modernization processes. All the interviews confirm that the emigration of young people and the attractiveness that surround the big cities, act as poles of attraction for emigration. Another determinant factor is the perception of agriculture as an activity that does not improve economic status and quality of life.

\subsubsection{Agrobiodiversity Assessment}

The evaluation of the agrodiversity in the Assaragh oasis was carried out with questionnaires, designed to gather data relative to traditional crops representative of the TAS and integrated by field surveys and direct observation. This approach has already been applied in previous similar studies on agroecosystems in the Rif [73], Anti-Atlas [7] and in the south of Morocco [74]. The questionnaire makes it possible to explore the different farming layers and present a comprehensive inventory of the traditional crops (cereals, pulses, local landraces and varieties' diversity), as well as introduced varieties.

Assaragh TAS presents three main layers, two arboreal ones and an herbaceous one.

1. The main and superior tree layer is mainly composed by palm trees (Phoenix dactylifera). Moroccan oasis are known by their important varietal and genetic diversity of date palm trees [75-78], in fact Moroccan oases present more than 220 known varieties [79]. Palm trees on one side shade the plots and protect them from wind reducing soil dissecation; they provide mechanical protection from soil erosion and once dead they can be used as construction material for terraces and irrigation channels. Moreover they supply fodder to sheep and cattle that are raised in enclosures and fed 
with palm leaves mixed with alfalfa and vegetable waste. Several studies have shown essential and diverse bacterial communities associated with root palm tree systems [80,81]. The main arboreal layer close to wadi banks, in some spots, hosts ancient specimens of Celtis australis, Populus alba and Populus nigra as they can naturally occur where the hyporheic flow is more present.

2. The secondary arboreal layer is composed mainly by seven species of cultivated tree: olive (Olea europaea), almond (Prunus dulcis), apricot (Prunus armeniaca) pomegranate (Punica granatum), carob (Ceratonia siliqua), fig (Ficus carica) and apple (Malus pumila). The olive tree, identified by the farmers under the denomination of 'Zitoune' and the almond tree are the dominant species in the secondary layer. The olive variety Zitoune has been previously identified by genetic markers as 'Picholine marocaine' [82]. It is widely spread in Moroccan agroecosystems and largely appreciated by local farmers $[11,83]$. The preference for olive and almond trees is in agreement with what has been observed by Belarbi et al. [84] in Aoufouss oasis (South of Morocco).

3. The herbaceous layer hosts two species of cereals, wheat (Triticum turgidum), known locally under the denomination of 'Amazigh', and barley (Hordeum vulgare). This layer is dominated by alfalfa (Medicago sativa) used as fodder, and by eight types of vegetable plants destined for local consumption: tomato (Solanum lycopersicum), onion (Allium cepa), carrot (Daucus carota), eggplant (Solanum melongena), faba bean (Vicia faba), courgette (Cucurbita pepo), green pepper (Capsicum annuum) and leek (Allium ampeloprasum). Therefore, association of wheat and barley with other crops was found to be beneficial for sustainable agricultural practices [85]. Assaragh is known also for the production of high quality saffron (Crocus sativus), which is not possible to cultivate downstream of Assaragh, in the Aguinane TAS at an altitude of $300 \mathrm{~m}$ lower.

Small land plots (or absence of flat plots), in addition to the harsh environmental conditions of the Anti-Atlas region has led local farmers towards more efficient agricultural system management, by applying the concept of TAS combined with a polyculture crop (or multi-crop) production system which implies the association of seasonal and perennials crops (Figures 7 and 8; [7]).

Recently Assaragh, as many Moroccan oasis agroecosystems, experienced a loss in agrobiodiversity [74], attested by the regression or extinction of many cultivated crops. In the present case lens (Lens culinaris) and chickpea (Cicer arietinum) crops disappeared from Assaragh agroecosystems. These crops were grown until the late 1970s. This tendency of crops disappearance has been already documented in the Anti-Atlas TAS [7].

\section{Results}

\subsection{Geology Influences on TAS Structure}

The state of TAS is linked to several factors such as topography, land use, soil type and anthropogenic activity [86,87]. However, geology plays a huge role in limiting or promoting the destruction and abandonment of TAS [88]. In fact, the lithological nature of the formations can amplify or limit infiltration and runoff $[89,90]$ while the tectonic activity can influence the internal drainage capacity and the water supply of the aquifers. Generally, the geology is in favor of downstream TAS which can benefit from a slow release of water infiltrated through the faults and permeable formations on the upstream areas of the basin (see Figure 10).

\subsection{Climatic Trends and Rainy Days Reduction}

A clear reduction of rainy days has been observed and identified as an evident climate change signal. A progression of higher abandonment ratios from downstream to upstream ksours is, indeed, obvious (Table 2); this can be explained by a higher groundwater availability in the TAS downstream which receives water from all the drained area with respect to the upstream TAS which rely much more on rain irrigation. In this sense, a reduction of rainy days and an increase of drought periods can explain the higher abandonment ratio for Timdghart and Iguerda TAS (see Table 2). 


\subsection{Water Balance at the Basin Scale}

In many agroecosystems in Morocco, water availability has been considered as a limiting factor by many authors [91,92]. This is not the case of Assaragh since, as shown in Table 8, the hydrological balance at the basin scale, keeping into account the considerations developed previously for Iguerda and Timdghart TAS, allows a cultivation of the current cultivated surface added to the surface of the abandoned terraces. This fact does not mean that there is no reduction in water resources, however today a possible reduction in water resources does not compromise the possibility of cultivating and irrigating, as traditionally done, within the basin and more specifically in the Assasrgh TAS.

\subsection{Perception of Groundwater Resources}

Unstructured interviews and questionnaires have shown that there is a general agreement between people that Assaragh 'is blessed by a huge availability of water' and, in general, there seems to be a preference for modern irrigation and water withdrawal techniques as mapped in the loops $\mathrm{B}(\mathrm{wd})$, $\mathrm{R}(\mathrm{mt})$ and $\mathrm{R}(\mathrm{ws})$ in Figure 5.

Nowadays it is impossible to make a diachronic assessment of the quality and quantity of groundwater storage, however, a dynamic linked to water supply, similar to the reservoir effect observed by Di Baldassarre et al. [33] is noted, which hints a lack of perception by the population of a possible aquifer productivity reduction.

The reservoir effect refers to archetypes describing an over-reliance on water infrastructure which increases vulnerability, and therefore, increases the potential damage from water shortages. This phenomenon refers to the construction of reservoirs to reduce adverse effects in water shortage situations, while at the same time the supply-demand cycle describes instances where increasing water supply enables higher water demand, quickly offsetting the initial benefits of reservoirs.

By analogy, as the reservoir effect refers to volumes, the water supply effect refers to the flow rates and to the flexibility of water withdrawal for irrigation purposes, the two effects are compared in Figure 16. Greater flexibility in water withdrawal techniques and the ability to draw higher flows when necessary, increase systemic vulnerability by reducing the ability to cope with irregular irrigation flows during the year, and stress the aquifer. In this perspective, a reduction in groundwater recharge due to climate change could play a marginal and indirect role in the abandonment of traditional irrigation systems. A similar shift towards modern water withdrawal techniques has been already well documented by Lightfoot [93] in Tafilalt basin. However, a markedly cultural dynamic emerged from unstructured interviews.

It should also be noted that in the projects linked to the MGP, a modernization of agriculture and drip irrigation is also encouraged through economic incentives. From what has been observed in the field, drip irrigation seems to be problematic since the water-extremely rich in calcium carbonates and prone to leaving many deposits—could make the plants unusable in a few years.

\subsection{Demographic, Social and Cultural Dynamics}

It is well noted and documented by many authors and summarized by Silverstein [54] that 'the southeastern oases of Morocco since the 1940s have functioned as a veritable demographic pump, sending streams of labour migrants to northern cities and across the Mediterranean'.

An important dynamic of this archetype is the flux of money generated by emigrants towards their homeland ksour in order to build new houses—based in urban architectural styles—outside of the walled ksour, often in emerging oasis town centers supplied with electricity and running water. This is the case of Assaragh, which nowadays has a water distribution network and tap water in all of the households. This resulting spatial dispersion contributed to the enhancement of migration among the younger generations, who viewed such movement as a means of household development and modern wealth. The archetype illustrated by Silverstein [54], and summarized in Figure 17, emerged quite strongly from unstructured interviews and questionnaires as well as from demographic data. 
Although the balance of the population inside the basin has remained positive thanks to a high birth rate, the various villages have experienced a young male emigration.

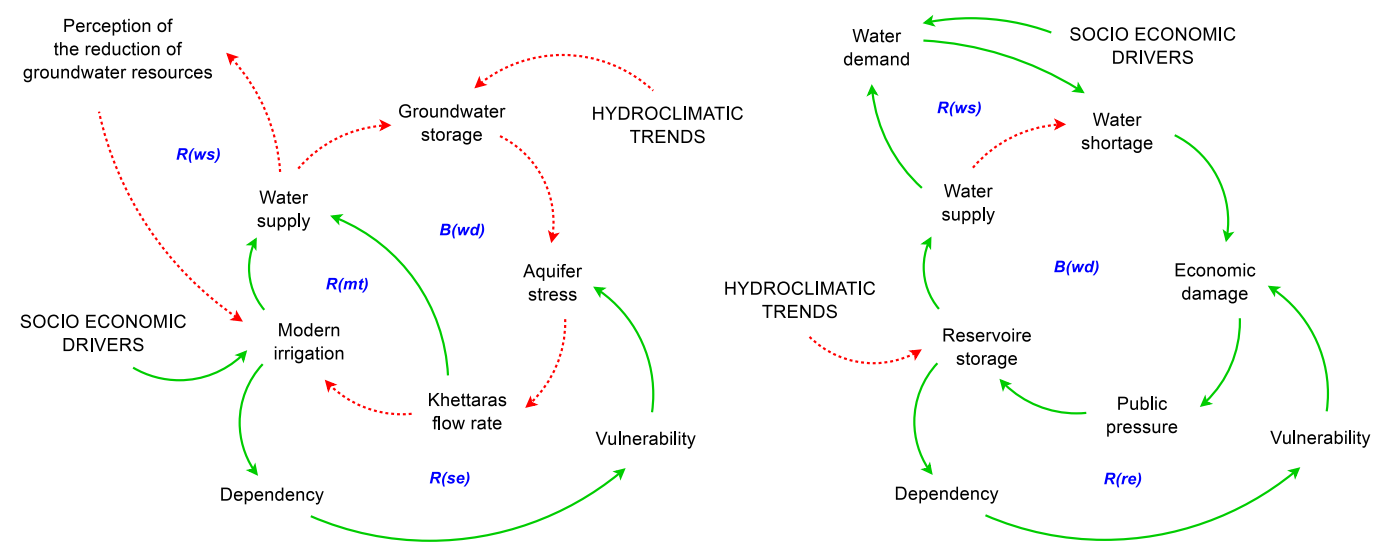

Figure 16. Comparison between two analogous archetypes. R(se) water supply effect (left casual loop diagram (CLD)) and $\mathrm{R}(\mathrm{re})$ reservoir effect (right CLD): in the water supply effect the feedback balancing loop $\mathrm{B}(\mathrm{wd})$ of water demand is overrun by $\mathrm{R}(\mathrm{mt})$ a shift towards modern water withdrawal techniques, to compensate for the aquifer productivity decrease, stressing even more the groundwater reservoir. An increase in water withdrawal can trigger a perception of abundant groundwater resources encouraging an even greater water withdrawal by means of modern wells and motor pumps R(ws). The reservoir effect $B(w d)$ is overrun by the $R(w s)$ water supply measures taken to mitigate water shortage.

The general effect on the SD of Assaragh TAS is a loss of traditional knowledge and a progressive weakening of terracing know-how due to the difficulties of cultural exchange between generations. A progressive weakening of terracing know-how directly increases the hydrogeological risk and reduces the preservation of traditional irrigation and organic matter in the TAS (see Figure 5).

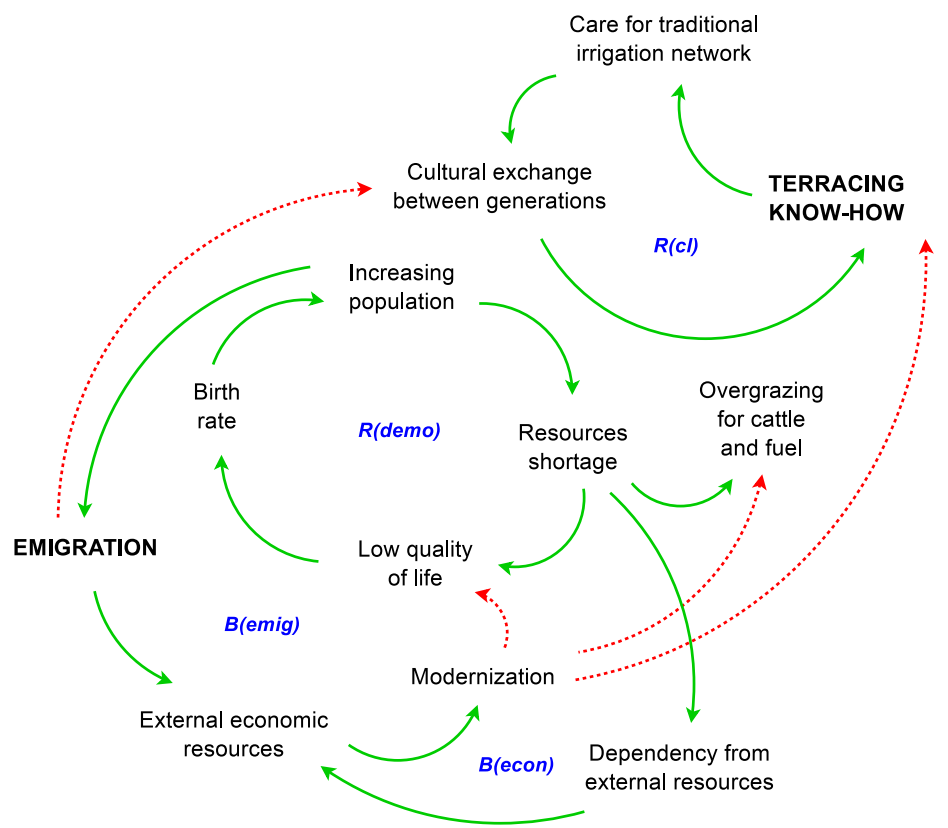

Figure 17. Archetype emerged by demographic, social and cultural dynamics mapped throughout Silverstein's observation and integrated with direct observation of the effects on Assaragh TAS. R(demo) is a positive feedback cycle increasing population, $\mathrm{R}(\mathrm{demo})$ already today is weakened by two negative feedback cycles, the $\mathrm{B}$ (econ) of economic dependency from emigrants sending money to the village and the $\mathrm{B}$ (emig), a cycle linked to the increase of population inside the ksours. Nowadays these cycle are weakened, with respect to the past, but still active and are confirmed by demographic data. 


\subsection{Mechanical Limitation of TAS Linked To Plant Growth}

A last important mapped dynamic links the structural integrity of the terraces with plant growth (Figure 18). As observed from the field surveys, plant growth can, in some cases, present destructive interaction with dry walls CLD B(rw), and this is the case of palm trees (Phoenix dactilifera) as shown in Figure 2a. However, plants can also present a reinforcing interaction with dry walls R(rww) and $\mathrm{R}$ (rwd), as was the case of caper (Capparis spinosa) (Figure 2b). In this sense, a proper equilibrium between vegetal species can play a determinant role in TAS conservation and expansion. It is important to note that the positive feedback loop R(rww) acts directly on soil moisture since the plants delay the percolation from the walls and most of the time shade the walls from solar radiation and wind.

\subsection{Global Dynamics Overview and Trends}

By observing the global dynamics in Assaragh TAS it is possible to sum up few trends: a generalized reduction of cultivated terraces more pronounced in peripheral areas of the TAS, a shifting towards more modern irrigation systems favoring a loss of care for the traditional ones. Despite a slow growth of the population within the ksours, a loss of interest for agricultural jobs among the young generation is observed, creating a push towards migration to large urban centers; the latter is weakening the cultural exchange between generations and leading to a loss of terracing know-how. Finally, a loss in agrobiodiversity is directly linked to the abandonment of terraces and of some cultivated varieties.

In general, it is possible to exclude that the abandonment of cultivated terraces in Assargh TAS is directly linked to a water shortage or to climate change, however the fact that a reduction in rainy days might have played a role in the abandonment of Iguerda and Timdghart TAS, cannot be excluded. In this sense climate change could lead to emerging problems related to water resources shortage in a future scenario, problems, which can accelerate TAS degradation and abandonment.

The CLD (Figure 5) indicates possible actions to counteract adverse effects of climate change in the promotion of terracing know-how to enhance the retention of organic matter and soil moisture, favoring agrobiodiversity and the expansion of transitional zone, hence the TAS stability and the selection of drought resistant varieties [58,59].

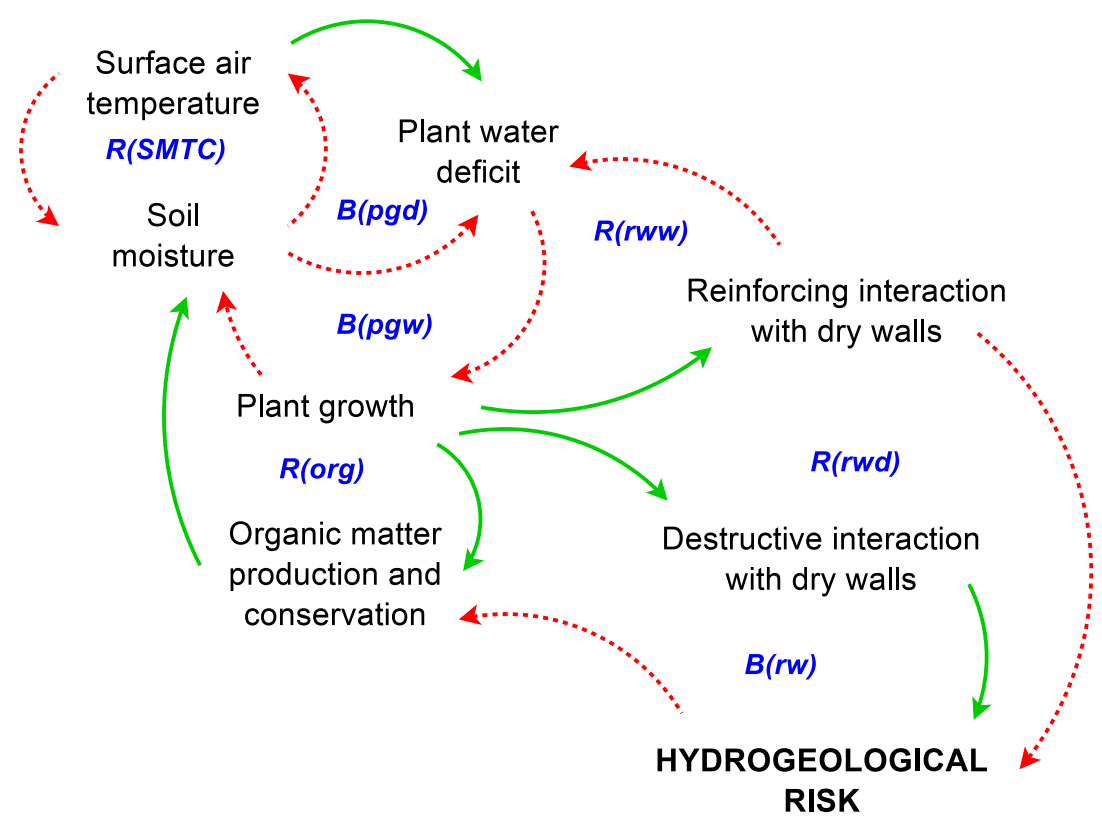

Figure 18. Map of positive interactions with dry walls $R(r w w)$ and $R(w r d)$ and destructive interaction with dry walls $\mathrm{B}(\mathrm{rw})$. The CLDs $\mathrm{R}(\mathrm{rww})$ and $\mathrm{R}(\mathrm{wrd})$ can play a role in TAS expansion and conservation whilst $\mathrm{B}(\mathrm{rw})$ plays a limiting role in TAS's expansion and conservation. 


\section{Discussion}

\subsection{Possible Actions for Local Initiatives and Policy Makers}

Since the main drivers in the investigated case were social and cultural rather than climatic and water resources related, three main actions are suggested in order to favor the cultural exchange between generations into preserving terracing know-how, and the promotion of adaptation strategies through the selection of drought-resistant varieties.

1. Local primary schools that are generally present in the small ksour community, can offer many possibilities of developing programs aimed at environmental and scientific education based on situated learning in the TAS. There is a vast literature on such experiences [94-97]. In fact, situated learning is useful not only to teach basic scientific notions, but to promote cultural exchange, as well. Moreover, school activities related to traditional agriculture and irrigation practices can help to build and reinforce the identity of young people [20] hence preserving local culture and developing the social potential of new generations.

2. The fundamental role of women in preserving crop productivity, traditional knowledge and achieving food security worldwide in rural communities has been widely recognized by the scientific community [98-101]. This is also valid in Amazigh communities [102] which today are observing a new rise of women involvement in local politics and social activism [103], thanks also to a process of modernization of a society which has become extremely patriarchal, following historical processes of social and cultural evolution [54]. However, in the past the Amazigh society has always had great female leaders who at times have emerged even in the historical periods most unfavorable to the emancipation of women [103]. In this sense the first action suggested views the empowerment of women in primary education, cultural exchange, TAS management and varieties selection, as a natural following action to take in order to consolidate the expected outcomes of the first one.

3. The need for continuous communication and research of innovative educational and participatory tools to interest the new generations and render the actions of women and local communities more effective is vital. In this way the academic community can play a fundamental role through citizen science activities $[104,105]$, in order to empower the two proposed actions. In fact, the third action consists in the creation of scientific participated laboratories in rural communities, laboratories that, in addition to promoting educational methodologies related to the environment and STEMs, promote citizen science projects aimed at the selection and the exchange of plant varieties suitable for future climate scenarios [106-108].

\subsection{Strengths and Limitations of $S D$}

The strengths of the applied SD methodology lies in its possibility to connect different fields and disciplines and its holistic overview to very complex problems. In general, its ability to integrate quantitative and qualitative data and to address issues step-by-step, offers opportunities to deepen the study of specific problems without losing a global perspective of the case study.

On the other side, the SD methodology needs to be implemented step-by-step for every case. In this specific case, it required a lot of field work to create a model valid and representative of the real dynamics. The SD modeling process has been iterated three times in order to reach a proper representation through CLD, while more complex case studies can require a higher number of iterations. In general the methodology should be implemented when several aspects concerning the case study have already been analyzed separately and there is a need for integrating them. A shift from a multidisciplinary to an interdisciplinary perspective can be cumbersome because of different lexicon and mindsets of the scientists working on the problem and often the shift can be incomplete resulting in a weak connection of single analysis of different disciplines. 
However, the methodology can still present an effective overview of the problem and can be very useful in decision making policies. As a reminder Forrester [35] already studied the methodology's drawbacks and advantages, recalling the decision making-oriented nature of SD: 'System dynamics combines the theory, methods and philosophy needed to analyze the behavior of systems in not only management, but also in environmental change, politics, economic behavior, medicine, engineering and other fields. System dynamics provide a common foundation that can be applied wherever researchers want to understand and influence how things change through time. The system dynamics process starts from a problem to be solved, a situation that needs to be better understood, or an undesirable behavior that is to be corrected or avoided. The first step is to tap the wealth of information that people possess in their heads. The mental database is a rich source of information about the parts of a system, about the information available at different points in a system, and about the policies being followed in decision making'. In this sense, an expansion of the literature of similar or contiguous case studies issues and solutions can be a good indication for addressing future research.

\section{Conclusions}

In this paper, the possible driving forces that can act upon the Assaragh TAS state have been identified and mapped through an SD framework, allowing the conceptualization of such a complex problem. Additionally, actions to counteract TAS degradation have been proposed. From the analysis-carried out through field surveys, interviews, questionnaires and freely accessible datasets-it emerged that the dynamics of TAS degradation in Assaragh, were led mainly by social and cultural drivers and very marginally from drivers related to climate change. Future threats emerged in relation to climate change, mainly linked to a possible water scarcity in the future, and to the loss of traditional farming knowledge leading to a genetic erosion of plant varieties and loss of agrobiodiversity.

Similar dynamics were also observed in the rural abandonment that occurred in the north of the Mediterranean during the post-war economic boom [12]. In the investigated case, what changes is the risks related to climate change and food security that must be addressed through forward-looking policies and prudent planning.

Some authors, among others Castelli et al. [60], have demonstrated that changes made in a landscape, may impact on the local climate, and that in arid and semi-arid agroecosystems, Landscape Restoration and Water Harvesting (LRWH) measures can revert land degradation and increase agricultural yields, by means of reducing runoff losses and increasing soil moisture. In this sense, terracing is, indeed, an LRWH technique under all aspects and must be promoted, where appropriate, to stabilize agricultural output on local communities facing climate change threats.

Marginal agricultural communities facing these threats are often found in areas, as in the present case study, where the lack of data can be considered systematic. With this study a quantitativequalitative methodology was developed that would allow the estimation of missing parameters in a reasonable manner. However, expanding the bibliography of case studies to well-instrumented arid and semi-arid basins, even in small scale cases, would greatly facilitate the analysis of the phenomena occurring in completely isolated basins, representative of the TAS in many marginal areas of Morocco.

It is also worth mentioning that the bibliography on the interactions between root systems, vegetation and LRWH structures is, indeed, lacking. Especially in the case of Assaragh, the role of vegetation is fundamental, as it is structural not only to the ecosystem itself but also to the geotechnical and functional dynamics of the man-made structures. Deepening the multidisciplinary studies in this direction, by integrating geotechnics and biology, could facilitate the improvement of LRWH techniques especially in relation to terraced landscapes.

Finally, the high unemployment rate observed in some study areas offers the possibility of developing professional figures dedicated to the recovery and development of TAS by means of novel LRWH techniques, not only in terms of agricultural production, but also in terms of educational, cultural and touristic development. 
Author Contributions: Conceptualization, V.B.; methodology, V.B.; software, V.B. and A.O.; validation, E.M.M. and A.E.O.; formal analysis, V.B., A.O., H.B., M.H. and J.K.; investigation, V.B., M.H. and J.K.; resources, V.B.; data curation, V.B. and E.M.M.; writing-original draft preparation, V.B. and E.M.M.; writing-review and editing, V.B., E.M.M., A.O., H.B., J.K., A.E.O., M.H.; visualization, V.B.; supervision, V.B. and E.M.M.; project administration, V.B.; funding acquisition, V.B. All authors have read and agreed to the published version of the manuscript.

Funding: This study has been funded by V.B. with his Ph.D. research fund from the Università degli Studi di Brescia and with his personal resources.

Acknowledgments: The help offered by Aicha Id Lahcen and her family during the field missions, their kind hospitality, as well as their assistance in remote data collection during the Covid-19 quarantine has been determinant to complete the present work. Special thanks to Mohammed Ater, from the Universite Abdelmalek Essaâdi in Tetouan, and his Equipe Bio-Agrodiversité for the fraternal support and hospitality offered.

Conflicts of Interest: The authors declare no conflict of interest.

\section{Abbreviations}

The following abbreviations are used in this manuscript:

$\begin{array}{ll}\text { CLD } & \text { Casual Loop Diagram } \\ \text { LRWH } & \text { Landscape Restoration and Water Harvesting } \\ \text { MGP } & \text { Morocco Green Plan } \\ \text { SD } & \text { System Dynamics } \\ \text { SMTC } & \text { Soil-Moisture Temperature Coupling } \\ \text { TAS } & \text { Terraced Agroecosystem }\end{array}$

\section{Appendix A. Glossary from Wadi Hydrology}

Wadi: It refers to a dry (ephemeral) riverbed or creek, in climates ranging from hyper-arid to sub-arid, that
contains water only when heavy rain occurs and can present hyporheic flow during the rest of the year.
Assif:
It refers to the main branch of the hydrographic network and can be considered as the main wadi.
Generally it is the closing section. In the case of an endorheic basin it coincides with the area that
collects the outflow.
Khettara: It is the local version of a qanat (Remini 2015 [109]), and it is made by a gently sloping underground
channel to transport water from an aquifer or water well to the surface; this technique does not stress
the aquifer, naturally draining it, avoiding forced water withdrawal.

\section{Appendix B. Demographic Details}

Census summary concerning all the ksours and the population living along the assif Aguinane. Data are from RGPH (2014) [64] census campaign.

Table A1. Census and occupational data of the population living along the assif Aguinane. Ksours are listed from upstream to downstream. The occupational status can be: employer, freelancer (in majority farmers), employee in public sector, employee in private sector, familiar care, member of a cooperative and other [64].

\begin{tabular}{lccccccccccc}
\hline & \multicolumn{3}{l}{ Demography } & \multicolumn{1}{c}{ Occupational Status for at Least 15 Years (\%) } \\
\hline Ksour & Pop. & Families & M & F & Empr. & Free. & Publ. & Empl. & Fami. & Coop. & Other \\
\hline Timdghart & 340 & 64 & 161 & 179 & 0.0 & 42.9 & 1.9 & 25.7 & 27.6 & 1.9 & 0.0 \\
Iguerda & 289 & 48 & 142 & 147 & 0.0 & 6.8 & 2.3 & 39.4 & 0.8 & 50.0 & 0.8 \\
Lemdint & 403 & 86 & 170 & 233 & 0.0 & 48.3 & 1.7 & 14.5 & 35.5 & 0.0 & 0.0 \\
Assaragh & 298 & 60 & 141 & 157 & 0.0 & 42.9 & 1.9 & 25.7 & 27.6 & 1.9 & 0.0 \\
Fifred & 471 & 89 & 214 & 257 & 2.1 & 8.2 & 3.1 & 78.4 & 1.0 & 3.1 & 4.1 \\
Fighil & 264 & 53 & 119 & 145 & 0.0 & 25.0 & 9.4 & 50.0 & 0.0 & 15.6 & 0.0 \\
Azegza & 318 & 66 & 157 & 161 & 0.0 & 15.7 & 17.7 & 63.5 & 0.0 & 3.1 & 0.0 \\
Kiroute & 329 & 68 & 153 & 176 & 3.5 & 14.0 & 19.3 & 63.2 & 0.0 & 0.0 & 0.0 \\
Timzoughine & 163 & 36 & 77 & 86 & 0.0 & 19.2 & 11.5 & 57.7 & 7.7 & 0.0 & 3.8 \\
\hline
\end{tabular}




\section{Appendix C. Additional Calculations}

The time of concentration, $\mathbf{t}_{c}$, was estimated with various methods, as seen in Table A2. For the time of concentration using the SCS formula [110] it has been assumed conservative Curve Runoff $(\mathrm{CN})$ values ranging from 85 to 99 suitable for arid rocky terrain accounting for possible karstification.

Table A2. Time of concentration $\left(\mathbf{t}_{c}\right)$ estimates.

\begin{tabular}{ccc}
\hline Formula & $\mathbf{t}_{c}$ & Formula Calibrated on: \\
\hline Giandotti (1934) [111] & $5.6 \mathrm{~h}$ & North Italian basins with area between 170 and $70,000 \mathrm{~km}^{2}$ \\
Pilgrim and McDermott (1981) [112] & $4.1 \mathrm{~h}$ & Australian basins with area between 0.1 and $250 \mathrm{~km}^{2}$ \\
NRCS SCS (CN = 85) (1972) [110] & $3.3 \mathrm{~h}$ & Rural basins with maximum area of $16 \mathrm{~km}^{2}$ \\
NRCS SCS $(\mathrm{CN}=99)(1972)[110]$ & $1.7 \mathrm{~h}$ & Rural basins with A maximum area of $16 \mathrm{~km}^{2}$ \\
\hline
\end{tabular}

\section{Appendix D. Unstructured Data Collection}

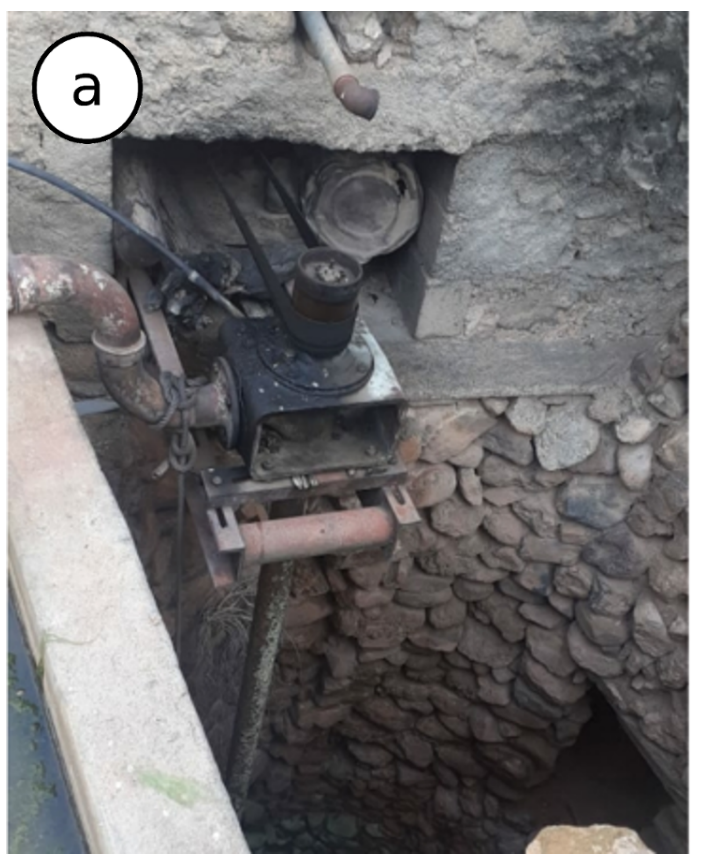

Figure A1. Wells for irrigation adopted in Assaragh: (b) and traditional.

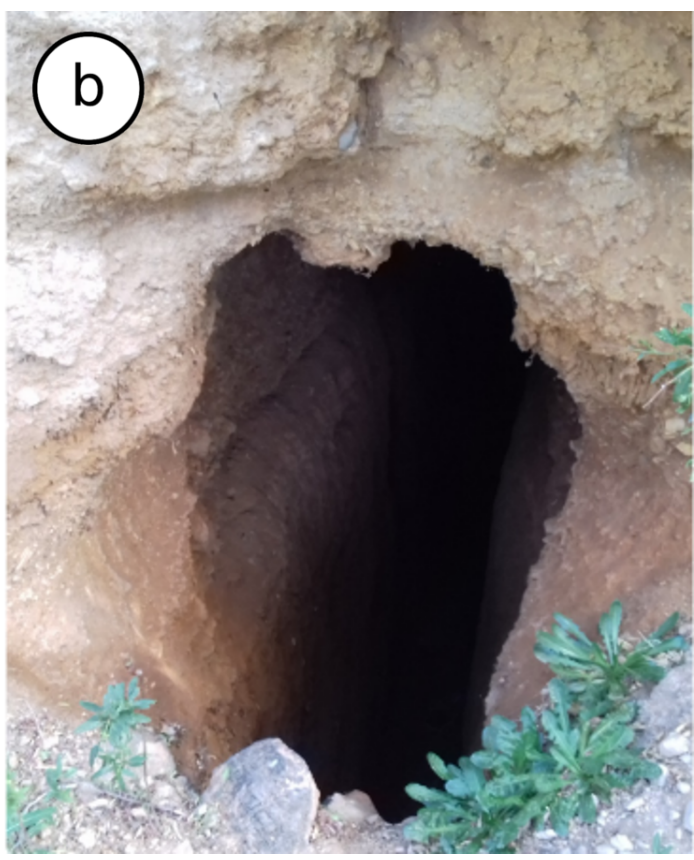

(a) modern with mechanical pump, 

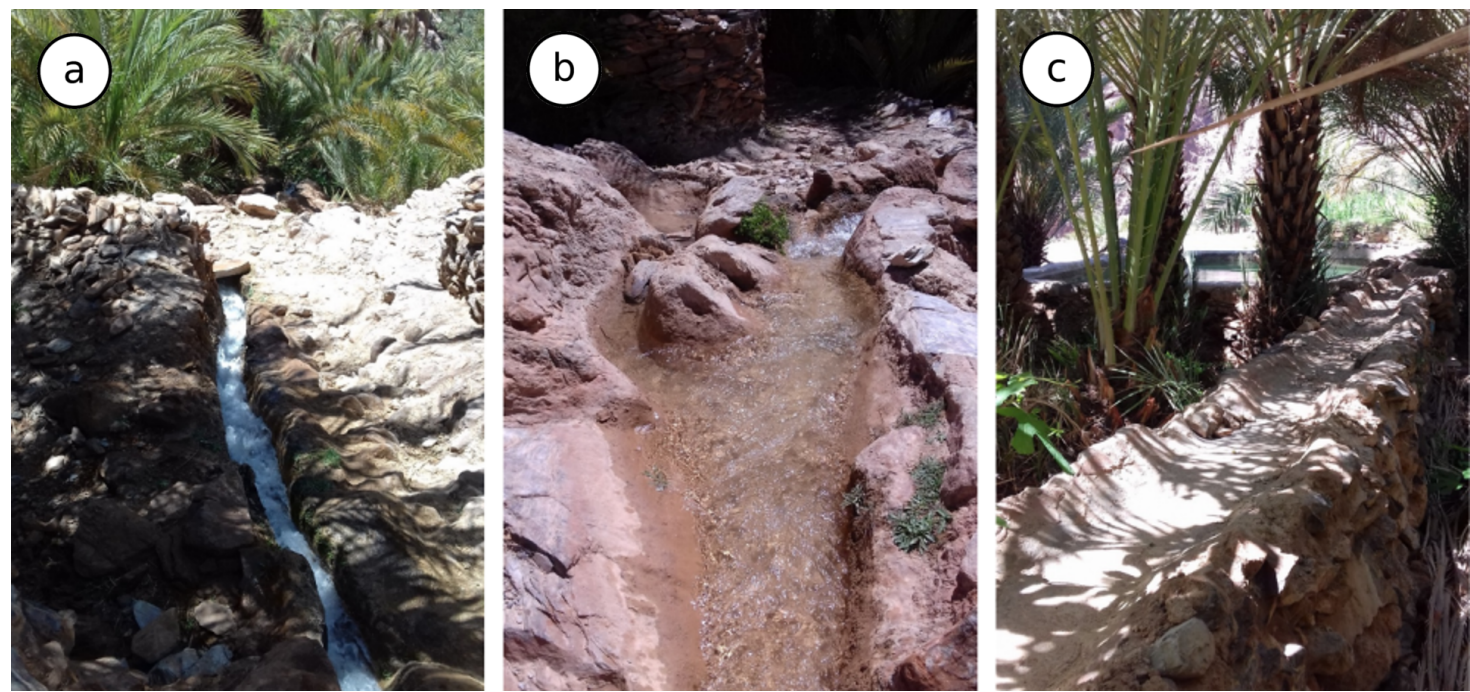

Figure A2. Traditional channels for water irrigation; the walls of the channels are covered by calcium carbonate natural deposits, due to the water filtration through the limestone in the basin. (a) A steep channel. (b) Bifurcation and repartition of the flow. (c) A horizontal channel built and naturally calcified on a dry stone wall.
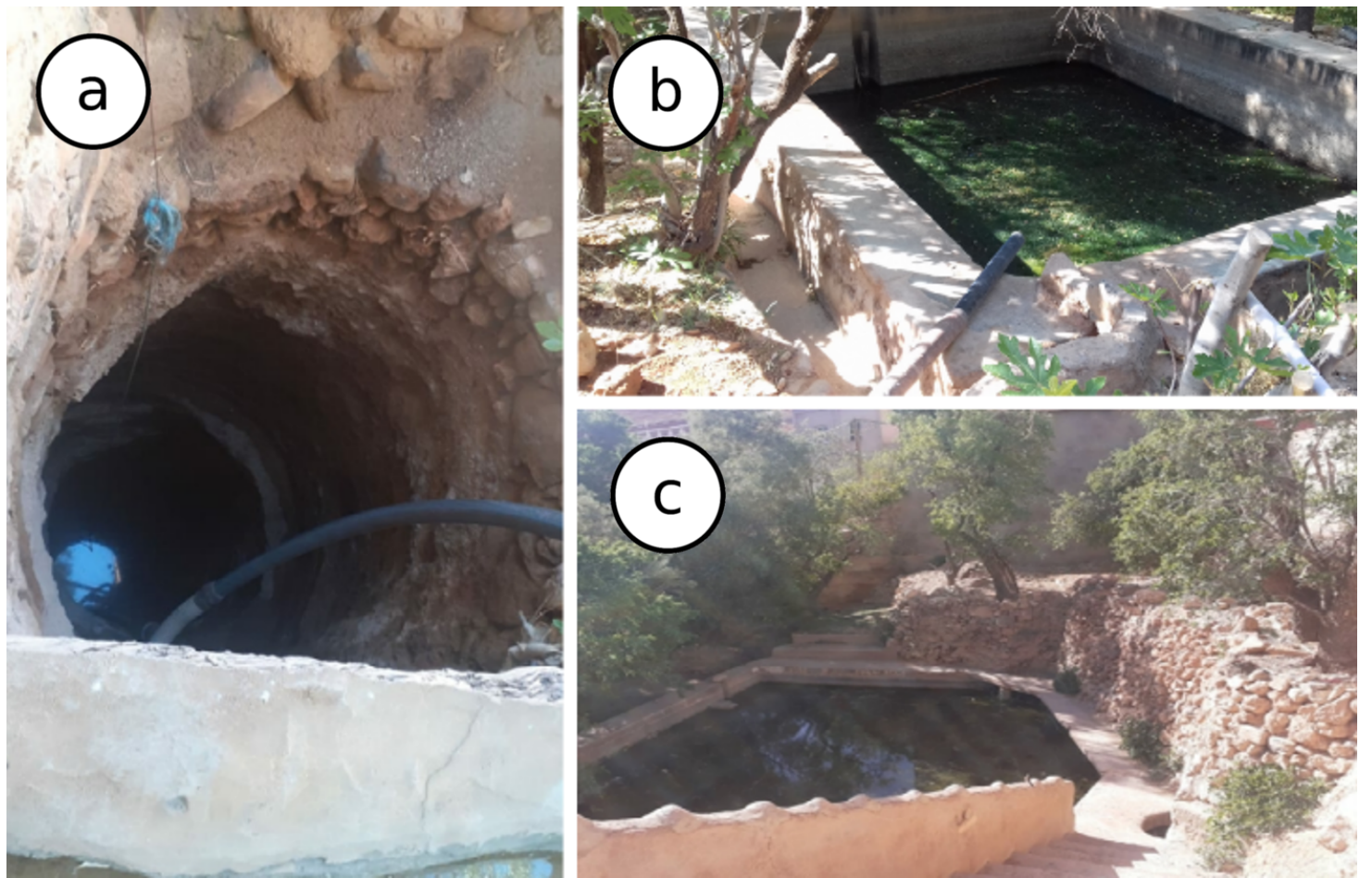

Figure A3. Nodes of the irrigation system. (a) A well with mechanical pump. (b) A modern and recent reservoir. (c) A traditional reservoir.

\section{Appendix E. Structured Data Collection}

Structured data collection has been divided in two parts, the first part is composed of a questionnaire (Tables A3 and A4) to map and validate some dynamics previously outlined, the second part was useful to evaluate the state of agrobiodiversity. For completeness, the questionnaires administered are shown with the average value of the responses and a summary table of each of the 15 individual interviewees. The different questions of the questionnaire are listed here and preceded by the average score obtained by each question. The average age of the interviewed persons is 61.3 years in a range from 41 to 75 years old. 
Table A3. Numeric answer.

\begin{tabular}{|c|c|}
\hline (2.2) & A-How many times during the year is the wadi flooded? \\
\hline (32) & B-How many days are rainy during the year? \\
\hline (250) & C-How many people live in the oasis (Assaragh and Lemdint)? \\
\hline (100) & $\begin{array}{l}\text { D-How many people were living in the oasis (Assaragh and Lemdint) when you were a child (from } 5 \text { to } 12 \\
\text { years old)? }\end{array}$ \\
\hline (88) & E-How many days were rainy during the year when you were a child (from 5 to 12 years old)? \\
\hline (32) & F-How many times during the year was the wadi flooded when you were a child (from 5 to 12 years old)? \\
\hline
\end{tabular}

Table A4. Answers on Likert's scale from 1 (total disagreement) to 5 (total agreement).

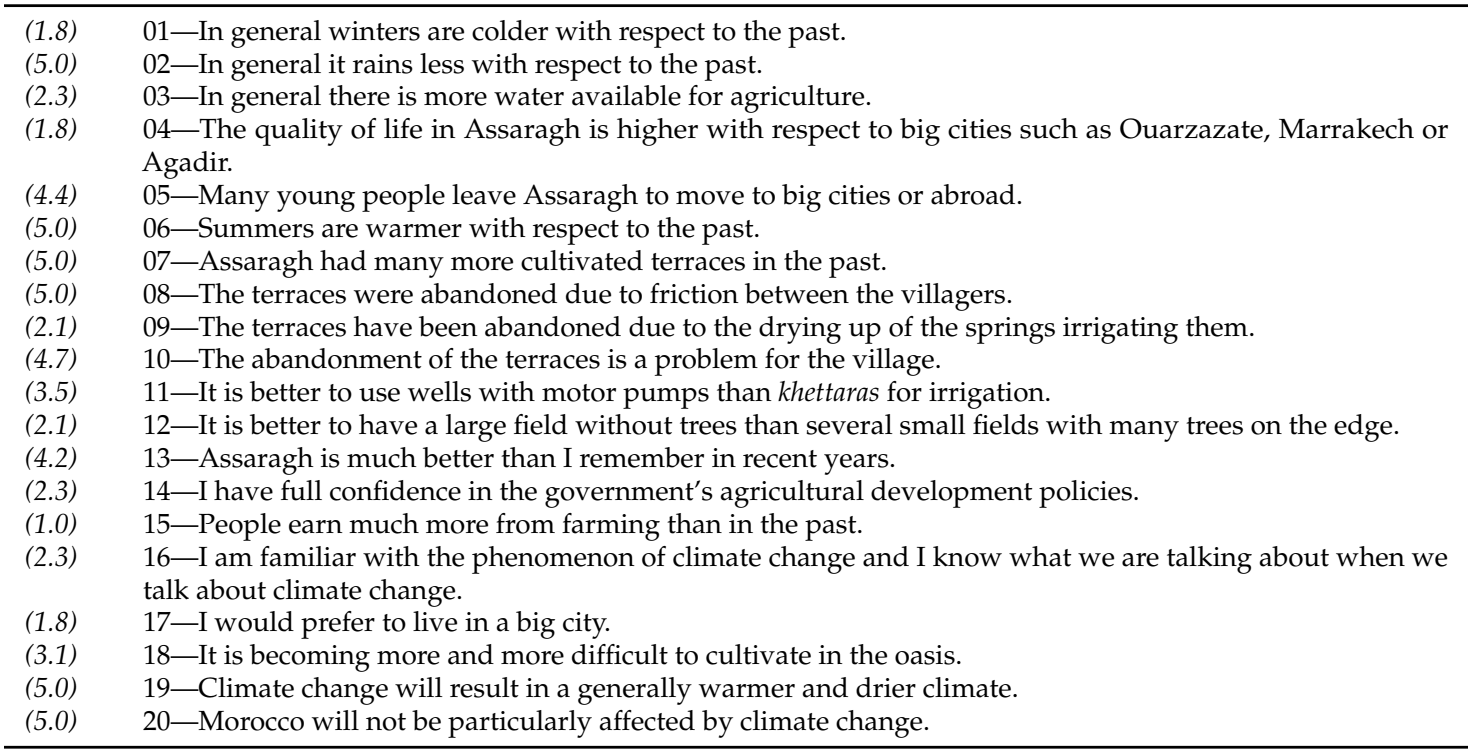

Table A5. Full results from the questionnaires; answers B, E and F were often given in range e.g., 90/120 or 40/50; the reported result is the average value of the range given.

\begin{tabular}{|c|c|c|c|c|c|c|c|c|c|c|c|c|c|c|c|}
\hline Entry & 01 & 02 & 03 & 04 & 05 & 06 & 07 & 08 & 09 & 10 & 11 & 12 & 13 & 14 & 15 \\
\hline Age & 57 & 66 & 62 & 68 & 75 & 69 & 70 & 45 & 77 & 62 & 61 & 58 & 41 & 56 & 62 \\
\hline Sex & $\mathrm{F}$ & $\mathrm{M}$ & $\mathrm{M}$ & $\mathrm{M}$ & $\mathrm{F}$ & $\mathrm{M}$ & $\mathrm{M}$ & $\mathrm{M}$ & $\mathrm{M}$ & $\mathrm{M}$ & $\mathrm{M}$ & $\mathrm{M}$ & $\mathrm{M}$ & $\mathrm{M}$ & $\mathrm{F}$ \\
\hline A & $2 / 3$ & $1 / 3$ & $2 / 3$ & $2 / 3$ & $1 / 3$ & $2 / 3$ & $2 / 3$ & $1 / 3$ & $1 / 3$ & $1 / 3$ & $1 / 3$ & $1 / 3$ & $1 / 3$ & $1 / 3$ & $1 / 3$ \\
\hline B & 30 & 35 & 30 & 40 & 30 & 30 & 40 & 30 & 30 & 30 & 30 & 30 & 30 & 30 & 35 \\
\hline$C$ & 250 & 250 & 250 & 250 & 250 & 250 & 250 & 250 & 250 & 250 & 250 & 250 & 250 & 250 & 250 \\
\hline D & 100 & 100 & 100 & 100 & 100 & 100 & 100 & 100 & 100 & 100 & 100 & 100 & 100 & 100 & 100 \\
\hline E & 90 & 105 & 60 & 90 & 120 & 105 & 120 & 60 & 90 & 90 & 90 & 60 & 60 & 90 & 90 \\
\hline $\mathrm{F}$ & 35 & 45 & 35 & 45 & 55 & 35 & 45 & 35 & 35 & 35 & 35 & 35 & 30 & 35 & 35 \\
\hline 01 & 5 & 5 & 1 & 1 & 5 & 1 & 1 & 1 & 1 & 1 & 1 & 1 & 1 & 1 & 1 \\
\hline 02 & 5 & 5 & 5 & 5 & 5 & 5 & 5 & 5 & 5 & 5 & 5 & 5 & 5 & 5 & 5 \\
\hline 03 & 1 & 1 & 1 & 1 & 5 & 5 & 5 & 5 & 1 & 1 & 5 & 1 & 1 & 1 & 1 \\
\hline 04 & 1 & 1 & 1 & 1 & 5 & 5 & 5 & 1 & 1 & 1 & 1 & 1 & 1 & 1 & 1 \\
\hline 05 & 4 & 4 & 4 & 4 & 3 & 4 & 5 & 4 & 4 & 5 & 5 & 5 & 5 & 5 & 5 \\
\hline 06 & 5 & 5 & 5 & 5 & 5 & 5 & 5 & 5 & 5 & 5 & 5 & 5 & 5 & 5 & 5 \\
\hline 07 & 5 & 5 & 5 & 5 & 5 & 5 & 5 & 5 & 5 & 5 & 5 & 5 & 5 & 5 & 5 \\
\hline 08 & 5 & 5 & 5 & 5 & 5 & 5 & 5 & 5 & 5 & 5 & 5 & 5 & 5 & 5 & 5 \\
\hline 09 & 1 & 1 & 1 & 1 & 5 & 1 & 5 & 1 & 5 & 1 & 1 & 1 & 1 & 5 & 1 \\
\hline 10 & 5 & 1 & 5 & 5 & 5 & 5 & 5 & 5 & 5 & 5 & 5 & 5 & 5 & 5 & 5 \\
\hline 11 & 1 & 5 & 5 & 5 & 1 & 5 & 1 & 4 & 1 & 4 & 5 & 1 & 4 & 5 & 5 \\
\hline 12 & 1 & 5 & 5 & 1 & 1 & 1 & 1 & 1 & 1 & 5 & 1 & 1 & 1 & 5 & 1 \\
\hline 13 & 5 & 5 & 5 & 5 & 1 & 1 & 5 & 1 & 5 & 5 & 5 & 5 & 5 & 5 & 5 \\
\hline 14 & 1 & 5 & 5 & 5 & 1 & 5 & 1 & 1 & 1 & 1 & 1 & 1 & 5 & 1 & 1 \\
\hline 15 & 1 & 1 & 1 & 1 & 1 & 1 & 1 & 1 & 1 & 1 & 1 & 1 & 1 & 1 & 1 \\
\hline 16 & 1 & 5 & 5 & 5 & 1 & 5 & 1 & 1 & 1 & 1 & 1 & 1 & 5 & 1 & 1 \\
\hline 17 & 1 & 5 & 1 & 1 & 1 & 1 & 1 & 1 & 1 & 1 & 1 & 1 & 5 & 1 & 5 \\
\hline 18 & 5 & 5 & 5 & 5 & 1 & 5 & 1 & 1 & 1 & 1 & 1 & 1 & 5 & 5 & 5 \\
\hline 19 & 5 & 5 & 5 & 5 & 5 & 5 & 5 & 5 & 5 & 5 & 5 & 5 & 5 & 5 & 5 \\
\hline 20 & 5 & 5 & 5 & 5 & n.a. & 5 & 5 & 5 & 5 & 5 & 5 & 5 & 5 & 5 & 5 \\
\hline
\end{tabular}




\section{References}

1. Healy, P.F.; Lambert, J.D.H.; Arnason, J.T.; Hebda, R.J. Caracol, Belize: Evidence of Ancient Maya Agricultural Terraces. J. Field Archaeol. 1983, 10, 397-410. [CrossRef]

2. Sandor, J.A. Ancient agricultural terraces and soils. In Footprints in the Soil: People and Ideas in Soil History; Warkentin, B., Ed.; Elsevier: New York, NY, USA, 2006; pp. 505-534.

3. Petit, C.; Konold, W.; Höchtl, F. Historic terraced vineyards: Impressive witnesses of vernacular architecture. Landsc. Hist. 2012, 33, 5-28. [CrossRef]

4. Martin, C. Espaces en Terrasses et Prévention de Risques Naturels en Cévennes; Maison de la Géographie: Montpellier, France, 2006.

5. Puy, A.; García Avilés, J.M.; Balbo, A.L.; Keller, M.; Riedesel, S.; Blum, D.; Bubenzer, O. Drip irrigation uptake in traditional irrigated fields: The edaphological impact. J. Environ. Manag. 2017, 202, 550-561. [CrossRef] [PubMed]

6. Romero Martin, L.E.; Gonzalez Morales, A.; Ramon Ojeda, A. Towards a new valuation of cultural terraced landscapes: The heritage of terraces in the Canary Islands (Spain). ANNALES Ser. Hist. Sociol. 2016, 26, 499-512. [CrossRef]

7. Ziyadi, M.; Dahbi, A.; Aitlhaj, A.; El Ouahrani, A.; El Ouahidi, A.; Achtak, H. Terraced Agroforestry Systems in West Anti-Atlas (Morocco): Incidence of Climate Change and Prospects for Sustainable Development. In Climate Change-Resilient Agriculture and Agroforestry; Springer: Berlin/Heidelberg, Germany, 2019; pp. 1-19. [CrossRef]

8. Koohafkan, P.; Altieri, M.; Initiative, G. A Methodological Framework for the Dynamic Conservation of Agricultural Heritage Systems; Land and Water Division, The Food and Agriculture Organization (FAO) of the United Nations: Geneva, Switzerland, 2011; pp. 1-61.

9. Koohafkan, P.; Altieri, M.A. Globally Important Agricultural Heritage Systems: A Legacy for the Future; Food and Agriculture Organization of the United Nations: Rome, Italy, 2011.

10. UNESCO. UNESCO Examination of nominations for inscription in 2018 on the Representative List of the Intangible Cultural Heritage of Humanity. In Document ITH/18/13.COM/10.b; UNESCO: London, UK, 2018.

11. Hmimsa, Y.; Ater, M. Agrodiversity in the traditional agrosystems of the Rif mountains (north of Morocco). Biodiversity 2008, 9, 78-81. [CrossRef]

12. Tarolli, P.; Preti, F.; Romano, N. Terraced landscapes: From an old best practice to a potential hazard for soil degradation due to land abandonment. Anthropocene 2014, 6, 10-25. [CrossRef]

13. Ater, M.; Hmimsa, Y. Agrodiversité des agroécosystèmes traditionnels du pays Jbala (Rif, Maroc) et produits de terroirs. In Indications Géographiques, Dynamiques Socio-Économiques et Patrimoine Bio-Culturel en Turquie et Dans les Pays Méditerranéens. Options Méditerranéennes A; Ilbert, H., Tekelioglu, Y., Çagatay, S., Tozanli, S., Eds.; CIHEAM: Antalya, Turkey, 2013; Volume 104, pp. 197-208.

14. Nair, P. An Introduction to Agroforestry; Kluwer Academic Publishers: Dordrecht, The Netherlands, $1993 ;$ p. 499.

15. De Haas, H. Migration and Agricultural Transformations in the Oases of Morocco and Tunisia; KNAG: Utrecht, The Netherlands, 2001.

16. Myers, N.; Mittermeier, R.A.; Mittermeier, C.G.; Da Fonseca, G.A.B.; Kent, J. Biodiversity hotspots for conservation priorities. Nature 2000, 403, 853. [CrossRef]

17. Brush, S.B. In situ conservation of landraces in centers of crop diversity. Crop Sci. 1995, 35, 346-354. [CrossRef]

18. Achtak, H.; Ater, M.; Oukabli, A.; Santoni, S.; Kjellberg, F.; Khadari, B. Traditional agroecosystems as conservatories and incubators of cultivated plant varietal diversity: The case of fig (Ficus carica L.) in Morocco. BMC Plant Biol. 2010, 10, 28. [CrossRef]

19. Liu, S.L.; Dong, Y.H.; Li, D.; Liu, Q.; Wang, J.; Zhang, X.L. Effects of different terrace protection measures in a sloping land consolidation project targeting soil erosion at the slope scale. Ecol. Eng. 2013, 53, 46-53. [CrossRef]

20. Barontini, S.; Boselli, V.; Louki, A.; Ben Slima, Z.; Ghaouch, F.E.; Labaran, R.; Raffelli, G.; Peli, M.; Al Ani, A.M.; Vitale, N.; et al. Bridging Mediterranean cultures in the International Year of Soils 2015: A documentary exhibition on irrigation techniques in water scarcity conditions. Hydrol. Res. 2017, 48, 789-801. [CrossRef] 
21. Arnáez, J.; Lasanta, T.; Errea, M.P.; Ortigosa, L. Land abandonment, landscape evolution, and soil erosion in a Spanish Mediterranean mountain region: The case of Camero Viejo. Land Degrad. Dev. 2011, 22, 537-550. [CrossRef]

22. Barrow, C.J.; Hicham, H. Two complimentary and integrated land uses of the western High Atlas Mountains, Morocco: The potential for sustainable rural livelihoods. Appl. Geogr. 2000, 20, 369-394. [CrossRef]

23. Agnoletti, M.; Errico, A.; Santoro, A.; Dani, A.; Preti, F. Terraced landscapes and hydrogeological risk. Effects of land abandonment in Cinque Terre (Italy) during severe rainfall events. Sustainability 2019, 11, 235. [CrossRef]

24. Kizos, T.; Koulouri, M.; Vakoufaris, H.; Psarrou, M. Preserving Characteristics of the Agricultural Landscape through Agri-Environmental Policies: The Case of Cultivation Terraces in Greece. Landsc. Res. 2010, 35, 577-593. [CrossRef]

25. Fischer, J.; Hartel, T.; Kuemmerle, T. Conservation policy in traditional farming landscapes. Conserv. Lett. 2012, 5, 167-175. [CrossRef]

26. Agnoletti, M.; Emanueli, F.; Errico, A.; Maggiari, G.; Santoro, A.; Preti, F. Terracing and hydrogeological risk. A study of the environmental disaster of 25 October 2011 in Cinque Terre. In Proceedings of the EGU General Assembly Conference, Vienna, Austria, 12-17 April 2015; Volume 17.

27. Alejano, L.R.; Veiga, M.; Taboada, J.; Díez-Farto, M. Stability of granite drystone masonry retaining walls: I. Analytical design. Géotechnique 2012, 62, 1013-1025. [CrossRef]

28. Galletti, C.S.; Ridder, E.; Falconer, S.E.; Fall, P.L. Maxent modeling of ancient and modern agricultural terraces in the Troodos foothills, Cyprus. Appl. Geogr. 2013, 39, 46-56. [CrossRef]

29. Ruhl, J.; Pasta, S. Plant succession on Sicilian terraces. Ann. Di Bot. 2007, 7. [CrossRef]

30. Martínez-Fernández, J.; Esteve-Selma, M.A.; Calvo-Sendín, J.F. Environmental and socioeconomic interactions in the evolution of traditional irrigated lands: A dynamic system model. Hum. Ecol. 2000, 28, 279-299.:1007024204961. [CrossRef]

31. Shahbazbegian, M.R.; Turton, A.; Mousavi Shafaee, S.M. Hydropolitical Self-Organization theory; system dynamics to analyse hydropolitics of Helmand transboundary river. Water Policy 2016, 18, 1088-1119. [CrossRef]

32. Tenza, A.; Gutiérrez Pérez, I.; Martínez-Fernández, J.; Arregui Giménez, A. Understanding the decline and resilience loss of a long-lived social-ecological system: Insights from system dynamics. Ecol. Soc. 2017, 22, 15. [CrossRef]

33. Di Baldassarre, G.; Wanders, N.; AghaKouchak, A.; Kuil, L.; Rangecroft, S.; Veldkamp, T.I.E.; Garcia, M.; van Oel, P.R.; Breinl, K.; Van Loon, A.F. Water shortages worsened by reservoir effects. Nat. Sustain. 2018, 1, 617-622. [CrossRef]

34. Sušnik, J.; Vamvakeridou-Lyroudia, L.S.; Savić, D.A.; Kapelan, Z. Integrated System Dynamics Modelling for water scarcity assessment: Case study of the Kairouan region. Sci. Total Environ. 2012, 440, 290-306. [CrossRef] [PubMed]

35. Forrester, J.W. System dynamics and the lessons of 35 years. In A Systems-Based Approach to Policymaking; De Greene, K.B., Ed.; Springer: Boston, MA, USA, 1993; pp. 199-240.

36. Buytaert, W.; Friesen, J.; Liebe, J.; Ludwig, R. Assessment and management of water resources in developing, semi-arid and arid regions. Water Resour. Manag. 2012, 26, 841-844. [CrossRef]

37. Barros, V.R.; Field, C.B. Climate Change 2014: Impacts, Adaptation, and Vulnerability. Part B: Regional Aspects; Cambridge University Press: Cambridge, UK, 2014.

38. Approaches to the Implementation of the Two Pillars of the MGP. Available online: https:/ / www.ada.gov. ma/en/approaches-implementation-two-pillars-green-morocco-plan (accessed on 30 May 2020).

39. His Majesty King Mohammed VI Launches the New Agricultural Strategy 'GENERATION GREEN 2020-2030'. Available online: https://www.ada.gov.ma/en/news/his-majesty-king-mohammed-vilaunches-new-agricultural-strategy-generation-green-2020-2030 (accessed on 30 May 2020).

40. Jenkins, T.N. Putting postmodernity into practice: Endogenous development and the role of traditional cultures in the rural development of marginal regions. Ecol. Econ. 2000, 34, 301-313. [CrossRef]

41. Schilling, J.; Freier, K.P.; Hertig, E.; Scheffran, J. Climate change, vulnerability and adaptation in North Africa with focus on Morocco. Agric. Ecosyst. Environ. 2012, 156, 12-26. [CrossRef]

42. Emberger, L. Une Classification Biogéographique des Climats; Recueil, Travaux de Laboratoire Géolo-Zoologique, Faculté des Sciences, Service Botanique: Montpellier, France, 1955; Volume 7, pp. 3-43. 
43. Rankou, H.; Culham, A.; Jury, S.L.; Christenhusz, M.J.M. The endemic flora of Morocco. Phytotaxa 2013, 78, 1-69. [CrossRef]

44. Benabid, A. Les Écosystèmes Forestiers, Préforestiers et Presteppiques du Maroc: Diversité, Répartition Biogéographique et Problèmes Posés par leur Aménagement; Forêt Méditerranéenne: Marseille, France, 1985.

45. Benabid, A. Flore et Écosystèmes du Maroc: Evaluation et Préservation de la Biodiversité; Ibis Press: Paris, France, 2000.

46. Senge, P.M. The Fifth Discipline Fieldbook: Strategies and Tools for Building a Learning Organization; Crown Business: New York, NY, USA, 2014.

47. Richardson, G.P. Feedback Thought in Social Science and Systems Theory; University of Pennsylvania: Philadelphia, PA, USA, 1991.

48. Wolstenholme, E.F. Towards the definition and use of a core set of archetypal structures in system dynamics. Syst. Dyn. Rev. 2003, 19, 7-26. [CrossRef]

49. Mirchi, A.; Madani, K.; Watkins, D.; Ahmad, S. Synthesis of system dynamics tools for holistic conceptualization of water resources problems. Water Resour. Manag. 2012, 26, 2421-2442. [CrossRef]

50. Wolstenholme, E.F. Qualitative vs quantitative modelling: The evolving balance. J. Oper. Res. Soc. 1999, 50, 422-428. [CrossRef]

51. Pruyt, E.; Cunningham, S.; Kwakkel, J.H.; De Bruijn, J.A. From data-poor to data-rich: System dynamics in the era of big data. In Proceedings of the 32nd International Conference of the System Dynamics Society, Delft, The Netherlands, 20-24 July 2014.

52. Prusty, B.A.K.; Chandra, R.; Azeez, P.A. Wetland Science: Perspectives From South Asia; Springer: Berlin/Heidelberg, Germany, 2017; p. 297.

53. Moulds, S.; O'Keeffe, J.; Djordjevic, S.; Savic, D. Towards a system dynamics model of the Indo-Gangetic Plain for sustainable water resources management. In AGU Fall Meeting Abstracts; AGU: Washington, DC, USA, 2018.

54. Silverstein, P.A. The diaspora and the cemetery: Emigration and social transformation in a Moroccan oasis community. J. N. Afr. Stud. 2015, 20, 92-108. [CrossRef]

55. Lal, R. Sequestering carbon in soils of arid ecosystems. Land Degrad. Dev. 2009, 20, 441-454. [CrossRef]

56. Bijlsma, R.; Loeschcke, V. Genetic erosion impedes adaptive responses to stressful environments. Evol. Appl. 2012, 5, 117-129. [CrossRef] [PubMed]

57. Xiaoling, P.; Jiping, C. Theory of stability, and regulation and control of ecological system in oasis. Glob. Planet. Chang. 2003, 37, 287-295. [CrossRef]

58. Benlaghlid, M.; Bouattoura, N.; Monneveux, P.; Borries, C. Les blés des oasis: Etude de la diversité génétique et de la physiologie de l'adaptation au milieu. In Les Systèmes Agricoles Oasiens; Dollé, V., Toutain, G., Eds.; CIHEAM: Tozeur, Tunisia, 1990; Volume 11, pp. 171-195.

59. Jouve, P. Les oasis du Maghreb, des agro-écosystèmes de plus en plus menacés. Comment renforcer leur durabilité? In Courrier de L'environnement de l'Inra; Institut National de la Recherche Agronomique Délégation Permanente à L'environnement: Paris, Italy, 2012.

60. Castelli, G.; Castelli, F.; Bresci, E. Mesoclimate regulation induced by landscape restoration and water harvesting in agroecosystems of the horn of Africa. Agric. Ecosyst. Environ. 2019, 275, 54-64. [CrossRef]

61. Earthdata-Earthdata Search. Available online: https:// earthdata.nasa.gov/ (accessed on 12 May 2019).

62. Stackhouse, P.W., Jr,; Zhang, T.; Westberg, D.; Barnett, A.J.; Bristow, T.; Macpherson, B.; Hoell, J.M. POWER Release 8.0. 1 (with GIS Applications) Methodology (Data Parameters, Sources, E Validation) Documentation Date December 12, 2018 (All Previous Versions Are Obsolete); Technical Report; NASA: Washington, DC, USA, 2018.

63. Reichle, R.H.; Liu, Q.; Koster, R.D.; Draper, C.S.; Mahanama, S.P.P.; Partyka, G.S. Land Surface Precipitation in MERRA-2. J. Clim. 2017, 30, 1643-1664. [CrossRef]

64. Recensement Générale de la Population et de l'Habitat au Maroc. 2014. Available online: http:/ / rgphentableaux. hcp.ma/ (accessed on 31 May 2020).

65. Nasri, S. Caractéristiques et impacts hydrologiques de banquettes en cascade sur un versant semi-aride en Tunisie centrale/Characteristics and hydrological impacts of a cascade of bench terraces on a semi-arid hillslope in central Tunisia. Hydrol. Sci. J. 2007, 52, 1134-1145. [CrossRef]

66. Strehmel, A.; Jewett, A.; Schuldt, R.; Schmalz, B.; Fohrer, N. Field data-based implementation of land management and terraces on the catchment scale for an eco-hydrological modelling approach in the Three Gorges Region, China. Agric. Water Manag. 2016, 175, 43-60. [CrossRef] 
67. Faure-Muret, A.; Choubert, G.; Dahmani, M.; El Mouatani, A.; Horrenberger, J.C.; Salem, M. Carte géologique du Maroc au 1/100 000-Feuille Agadir Melloul. In Notes et Mémoires n³59; Ministère de l’Énergie et des Mines: Rabat, Morocco, 1992.

68. Bazuhair, S.A.; Al-Gohani, A.; Şen, Z. Determination of monthly wet and dry periods in Saudi Arabia. Int. J. Climatol. 1997, 17, 303-311. [CrossRef]

69. Şen, Z. Wadi Hydrology; CRC Press: Boca Raton, FL, USA, 2008.

70. Steenhuis, T.S.; Van der Molen, W.H. The Thornthwaite-Mather procedure as a simple engineering method to predict recharge. J. Hydrol. 1986, 84, 221-229. [CrossRef]

71. Cargill, K.W. Mathematical Model of the Consolidation/Desiccation Processes in Dredged Material; Technical Report; Environmental Laboratory (US) and Engineer Research and Development Center (US): Vicksburg, MS, USA, 1985.

72. De Jong, C.; Cappy, S.; Finckh, M.; Funk, D. A transdisciplinary analysis of water problems in the mountainous karst areas of Morocco. Eng. Geol. 2008, 99, 228-238. [CrossRef]

73. Barontini, A.; Hmimsa, Y. Agrobiodiversité et pratiques agricoles dans le pays Jbala (Tafza et Bellota). Interaction entre ethnobotanique et linguistique. Revue d'ethnoécologie 2017. [CrossRef]

74. Ait Hmida, A. Systemes de production et stratégies des agriculteurs dans les oasis de la region d'Errachidia au Maroc. New Medit 2003, 2, 37-43.

75. Sedra, M.H. Le Palmier Dattier Base de la Mise en Valeur des Oasis au Maroc: Techniques Phoénicicoles et Création D'oasis; INRA Editions: Rabat, Morocco, 2003; p. 265.

76. Elhoumaizi, M.A.; Devanand, P.S.; Fang, J.; Chao, C.T. Confirmation of 'Medjool' date as a landrace variety through genetic analysis of 'Medjool' accessions in Morocco. J. Am. Soc. Hortic. Sci. 2006, 131, 403-407. [CrossRef]

77. Bodian, A.; El Houmaizi, M.A.; Ndoye Ndir, K.; Hasnaoui, A.; Nachtigall, M.; Wehling, P. Genetic diversity analysis of date palm (Phoenix dactylifera L.) cultivars from Figuig oasis (Morocco) using SSR markers. IJSAT 2012, 2, 96-104.

78. Harrak, H.; Hamouda, A.; Nadi, M. Évaluation et amélioration de la qualité des pâtes traditionnelles de dattes, produits du terroir des oasis. Cah. Agric. 2018, 27. [CrossRef]

79. Toutain, G.; Bachra, A.; Chari, A. Cartographie Variétale de la Palmeraie Marocaine; Technical Report; Direction de la Recherche Agronomique: Rabat, Morocco, 1971.

80. Ferjani, R.; Marasco, R.; Rolli, E.; Cherif, H.; Cherif, A.; Gtari, M.; Boudabous, A.; Daffonchio, D.; Ouzari, H.I. The date palm tree rhizosphere is a niche for plant growth promoting bacteria in the oasis ecosystem. BioMed Res. Int. 2015, 2015. [CrossRef]

81. Mosqueira, M.J.; Marasco, R.; Fusi, M.; Michoud, G.; Merlino, G.; Cherif, A.; Daffonchio, D. Consistent bacterial selection by date palm root system across heterogeneous desert oasis agroecosystems. Sci. Rep. 2019, 9, 1-12. [CrossRef]

82. Khadari, B.; Charafi, J.; Moukhli, A.; Ater, M. Substantial genetic diversity in cultivated Moroccan olive despite a single major cultivar: A paradoxical situation evidenced by the use of SSR loci. Tree Genet. Genomes 2008, 4, 213-221. [CrossRef]

83. Ater, M.; Barbara, H.; Kassout, J. Importance des variétés locales, de l'oléastre et des pratiques traditionnelles de l'oléiculture dans la région de Chefchaouen (Nord du Maroc). In L'oléiculture au Maroc de la Préhistoire à nos jours: Pratiques, Diversité, Adaptation, Usages, Commerce et Politiques. Options Méditerranéennes A; Ater, M., Essalouh, L., Ilbert, H., Moukhli, A., Khadari, B., Eds.; CIHEAM: Montpellier, France, 2016; Volume 118, pp. 109-121.

84. Belarbi, A.; Boayad, A.; Diaou, M.; Kaassiq, N.; Tidjani Miliki, M. Agrobiodiversité et Durabilité des Systèmes de Production Oasiens dans la Palmeraie d'Aoufouss Errachidia-Maroc; Technical Report; IRCA/INRA: Errachidia, Morocco, 2004.

85. Wezel, A.; Casagrande, M.; Celette, F.; Vian, J.; Ferrer, A.; Peigné, J. Agroecological practices for sustainable agriculture. A review. Agron. Sustain. Dev. 2014, 34,1-20. [CrossRef]

86. Gatot, I.; Perez, P.; Duchesne, J. Modelling the influence of irrigated terraces on the hydrological response of a small basin. Environ. Model. Softw. 2001, 16, 31-36. [CrossRef]

87. Calsamiglia, A.; Lucas-Borja, M.E.; Fortesa, J.; García-Comendador, J.; Estrany, J. Changes in soil quality and hydrological connectivity caused by the abandonment of terraces in a Mediterranean burned catchment. Forests 2017, 8, 333. [CrossRef] 
88. Jiao, Y.; Zhao, D.; Xu, Q.; Liu, Z.; Ding, Z.; Ding, Y.; Liu, C.; Zha, Z. Mapping lateral and longitudinal hydrological connectivity to identify conservation priority areas in the water-holding forest in Honghe Hani Rice Terraces World Heritage Site. Landsc. Ecol. 2020, 1-17. [CrossRef]

89. Lesschen, J.P.; Kok, K.; Verburg, P.H.; Cammeraat, L.H. Identification of vulnerable areas for gully erosion under different scenarios of land abandonment in Southeast Spain. Catena 2007, 71, 110-121. [CrossRef]

90. Arnáez, J.; Lana-Renault, N.; Lasanta, T.; Ruiz-Flaño, P.; Castroviejo, J. Effects of farming terraces on hydrological and geomorphological processes. A review. Catena 2015, 128, 122-134. [CrossRef]

91. Ait Khandouch, M. L'eau, facteur limitant de l'espace oasien. Le cas des oasis de Skoura et Amkchoud au sud du Maroc (The water: Limiting factor of the oasian space. The case of the oasis Skoura and Amkchoud in the south of Morocco). Bull. L'Assoc. Geogr. Fr. 2000, 77, 52-60. [CrossRef]

92. Bouras, E.; Jarlan, L.; Khabba, S.; Er-Raki, S.; Dezetter, A.; Sghir, F.; Tramblay, Y. Assessing the impact of global climate changes on irrigated wheat yields and water requirements in a semi-arid environment of Morocco. Sci. Rep. 2019, 9, 1-14. [CrossRef]

93. Lightfoot, D.R. Moroccan khettara: Traditional irrigation and progressive desiccation. Geoforum 1996, 27, 261-273. [CrossRef]

94. Krasny, M.E.; Tidball, K.G. Community gardens as contexts for science, stewardship, and civic action learning. Cities Environ. (CATE) 2009, 2,8.

95. Castle, J.; Osman, R.; Henstock, V. Coupling 'school experience' with community service: A case study. Educ. Chang. 2003, 7, 3-20.

96. Aguilar, O.M.; Krasny, M.E. Using the communities of practice framework to examine an after-school environmental education program for Hispanic youth. Environ. Educ. Res. 2011, 17, 217-233. [CrossRef]

97. Cuevas, M.V.; Milan, G.L.; Reid, A. Pedagogical implications of situated learning: Environmental workshops in rural Mexico. In The Child's World: Triggers for Learning; ACER Press: Camberwell, Australia, 2000; p. 344.

98. Cadima, X.; Terrazas, F.; Salazar, M.; Calderón, R.; Antezana, I.; Iriarte, V.; Ajnota, E.; Gonzales, R.; Ferrufino, N. Preserving biodiversity of Andean roots and tubers: Working with women. Innov. Dev. 2011, 354. Available online: http://hdl.handle.net/10625/49125 (accessed on 12 June 2020).

99. Ibnouf, F.O. The value of women's indigenous knowledge in food processing and preservation for achieving household food security in rural Sudan. J. Food Res. 2012, 1, 238. [CrossRef]

100. Matsa, W.; Mukoni, M. Traditional science of seed and crop yield preservation: Exploring the contributions of women to indigenous knowledge systems in Zimbabwe. Int. J. Humanit. Soc. Sci. 2013, 3, $234-245$.

101. FSN-Forum. Mainstreaming Gender for Sustainable Soil Management, Report of Activity $N^{\circ} 161$; Technical Report; FAO: Rome, Italy, 2019.

102. Belahsen, R.; Naciri, K.; El Ibrahimi, A. Food security and women's roles in Moroccan Berber (Amazigh) society today. Matern. Child Nutr. 2017, 13. [CrossRef]

103. Aït Frawsen, U.; Ukerdis, L. The Origins of Amazigh Women's Power in North Africa. Al-Raida J. 2003, 17-23. [CrossRef]

104. Marlanne, E. Environmental education through citizen science and participatory action research. In Environmental Education and Advocacy: Changing Perspectives of Ecology and Education; Cambridge University Press: Cambridge, UK, 2005; p. 292.

105. Wals, A.E.J.; Brody, M.; Dillon, J.; Stevenson, R.B. Convergence between science and environmental education. Science 2014, 344, 583-584. [CrossRef]

106. Thomas, M.; Dawson, J.C.; Goldringer, I.; Bonneuil, C. Seed exchanges, a key to analyze crop diversity dynamics in farmer-led on-farm conservation. Genet. Resour. Crop Evol. 2011, 58, 321-338. [CrossRef]

107. Bessette, G. Can Agricultural Citizen Science Improve Seed Systems? The Contributions of Crowdsourcing Participatory Variety Selection through On-Farm Triadic Comparisons of Technologies; Technical Report; ICRISAT: Hyderabad, India, 2018.

108. Van Etten, J.; Beza, E.; Calderer, L.; Van Duijvendijk, K.; Fadda, C.; Fantahun, B.; Kidane, Y.G.; Van de Gevel, J.; Gupta, A.; Mengistu, D.K.; et al. First experiences with a novel farmer citizen science approach: Crowdsourcing participatory variety selection through on-farm triadic comparisons of technologies (tricot). Exp. Agric. 2019, 55, 275-296. [CrossRef]

109. Remini, B.; Achour, B.; Albergel, J. The qanat of Algerian Sahara: An evolutionary hydraulic system. Appl. Water Sci. 2015, 5, 359-366. [CrossRef] 
110. Mockus, V. Design hydrographs. In National Engineering Handbook, Section 4, Hydrology; McKeever, V., Owen, W., Rallison, R., Eds.; USDA: Washington, DC, USA, 1972; Chapter 21.

111. Giandotti, M. Previsione delle piene e delle magre dei corsi d'acqua. In Memorie e Studi Idrografici; Servizio Idrografico Italiano: Rome, Italy, 1934.

112. Pilgrim, D.H.; McDermott, G.E. Design floods for small rural catchments in eastern New South Wales. In First National Local Government Engineering Conference 1981: Reprints of Papers; Institution of Engineers: Barton, Australia, 1981; p. 138.

(C) 2020 by the authors. Licensee MDPI, Basel, Switzerland. This article is an open access article distributed under the terms and conditions of the Creative Commons Attribution (CC BY) license (http:/ / creativecommons.org/licenses/by/4.0/). 